\title{
Recent Advances on Extracellular Vesicles in Central Nervous System Diseases
}

This article was published in the following Dove Press journal:

Clinical Interventions in Aging

\author{
Tao Jin' \\ Jiachen $\mathrm{Gu}^{\prime}$ \\ Zongshan $\mathrm{Li}^{\prime}$ \\ Zhongping $\mathrm{Xu}^{2}$ \\ Yaxing Gui ${ }^{1}$ \\ 'Department of Neurology, Sir Run Run \\ Shaw Hospital, School of Medicine, \\ Zhejiang University, Hangzhou, 310016, \\ People's Republic of China; ${ }^{2}$ Washington \\ University School of Medicine, St. Louis, \\ MO, 63II0, USA
}

\begin{abstract}
Extracellular vesicles (EVs) are particles released by multiple cells, encapsulated by lipid bilayers and containing a variety of biological materials, including proteins, nucleic acids, lipids and metabolites. With the advancement of separation and characterization methods, EV subtypes and their complex and diverse functions have been recognized. In the central nervous system (CNS), EVs are involved in various physiological and pathological processes, such as regulation of neuronal firing, synaptic plasticity, formation and maintenance of myelin sheath, propagation of neuroinflammation, neuroprotection, and spread and removal of toxic protein aggregates. Activity-dependent alteration of constituents enables EVs to reflect the change of cell and tissue states, and the wide distribution of EVs in biological fluids endows them with potential as diagnostic and prognostic biomarkers for CNS diseases, including neurodegenerative disease, cerebrovascular disease, traumatic brain disease, and brain tumor. Favorable biocompatibility, ability of crossing the blood-brain barrier and protecting contents from degradation, give promising therapeutic effects of EVs, either collected from mesenchymal stem cells culture conditioned media, or designed as drug delivery vehicles loaded with specific agents. In this review, we summarized EVs' basic biological properties, and mainly focused on their applications in CNS diseases.
\end{abstract}

Keywords: EVs, exosomes, CNS, blood-brain barrier, neurodegenerative disease, stroke

\section{Introduction}

Extracellular vesicles (EVs) are particles derived from biological system, enclosed by lipid bilayers and released by almost all cells to extracellular space. ${ }^{1}$ In the last four decades, remarkable progress has been made in the field of EVs. Nowadays, EVs research is mainly focused on three aspects. The first one is the methodological study, involving separation, enrichment and characterization of EVs or EV subtypes, originated from cell culture conditioned media or physiological fluids. In fact, more standardized experimental procedures are evolving and more novel experimental techniques are constantly emerging. ${ }^{2}$ The second aspect is the investigation of intrinsic properties and functions of EVs from the normal physiological processes in organism to pathological alterations in various diseases. The last one is to explore the application of EVs in diagnosis, prognosis and treatment. To some extent, these three aspects are interactional and gradually deepening.

The role of EVs in the central nervous system (CNS) is an issue still to be clarified. Structural and functional integrity of the CNS is based on interactions between neurons and glial cells through electrical activity, and anterograde or retrograde chemical signal. EVs can be released by neural stem/progenitor cells (NSCs/NPCs), ${ }^{3}$ neurons,
Correspondence: Yaxing Gui

Department of Neurology, Sir Run Run

Shaw Hospital, School of Medicine,

Zhejiang University, Hangzhou, 310016

People's Republic of China

Email guiyaxing@zju.edu.cn 
astrocytes, oligodendrocytes, and microglia, ${ }^{4,5}$ and at a broader level, participate in cell-cell communication, not only encompassing various signal molecules but more important, integrating the CNS with peripheral tissues and organs. Subsequent changes of the CNS both in physiological and pathological conditions probably reflect a "doubleedged sword" effect of EVs. Isolating brain-derived EVs in cerebrospinal fluid (CSF) or peripheral body fluids (plasma, serum, urine and saliva, etc.), detecting changes of specific molecules within EVs, delivering natural or engineered EVs loaded with therapeutic agents into the brain and targeting restricted lesions are hot spots in EV research. In this review, we gave an outline of EVs' basic properties first, which is a prerequisite for further research, and then the role and application in the CNS was launched at great lengths.

\section{Basic Properties of EVs Origin, Classification and Functions}

Generally, according to distinctions in size and origin, EVs are divided into three subtypes. ${ }^{6}$ Exosomes, with $40-160 \mathrm{~nm}$ in diameter, are generated from the endosome system. Transmembrane proteins are endocytosed along with the plasma membrane (PM) invagination, forming early endosome. Early endosome matures into late endosome and eventually transforms into multivesicular body (MVB). Limiting membrane of MVB invaginates to form intraluminal vesicles, and when MVB fuses with PM, they are released to the extracellular microenvironment, that is exosomes. Ectosomes or shedding microvesicles are formed by direct outward budding of PM, with 50-1000 nm in diameter. Figure 1 illustrates the different origins of these two subtypes. Apoptotic bodies, larger than the other two (50-5000 $\mathrm{nm}$ in diameter), are fragments of cells destined to apoptosis or programmed cell death. Though they were just regarded as a rapid elimination mode for cytoplasm and cell debris for a long time, some recent studies have disclosed that apoptotic bodies might also involve the transmission of information, especially in cancer field. ${ }^{7,8}$ Notably, based on current isolation, purification and analytical techniques, we always harvest heterogeneous EV populations in the end, implying that the conclusion pointed to a particular subtype of EV, such as exosomes, should be interpreted cautiously. ${ }^{9}$

Despite the existence of mixed subtypes, the most important function, that is intercellular communication, has been recognized based on the broader concept of EVs. Actually, the above function is the basis of various physiological and pathological processes associated with EVs, including immune response and tumor formation. ${ }^{10,11}$ Intercellular communication mediated by EVs covers vesicles secretion, long or short-distance trafficking, uptake by recipient cells and further intracellular effects. Whether formation route is double invagination or direct budding of PM, transmembrane proteins and
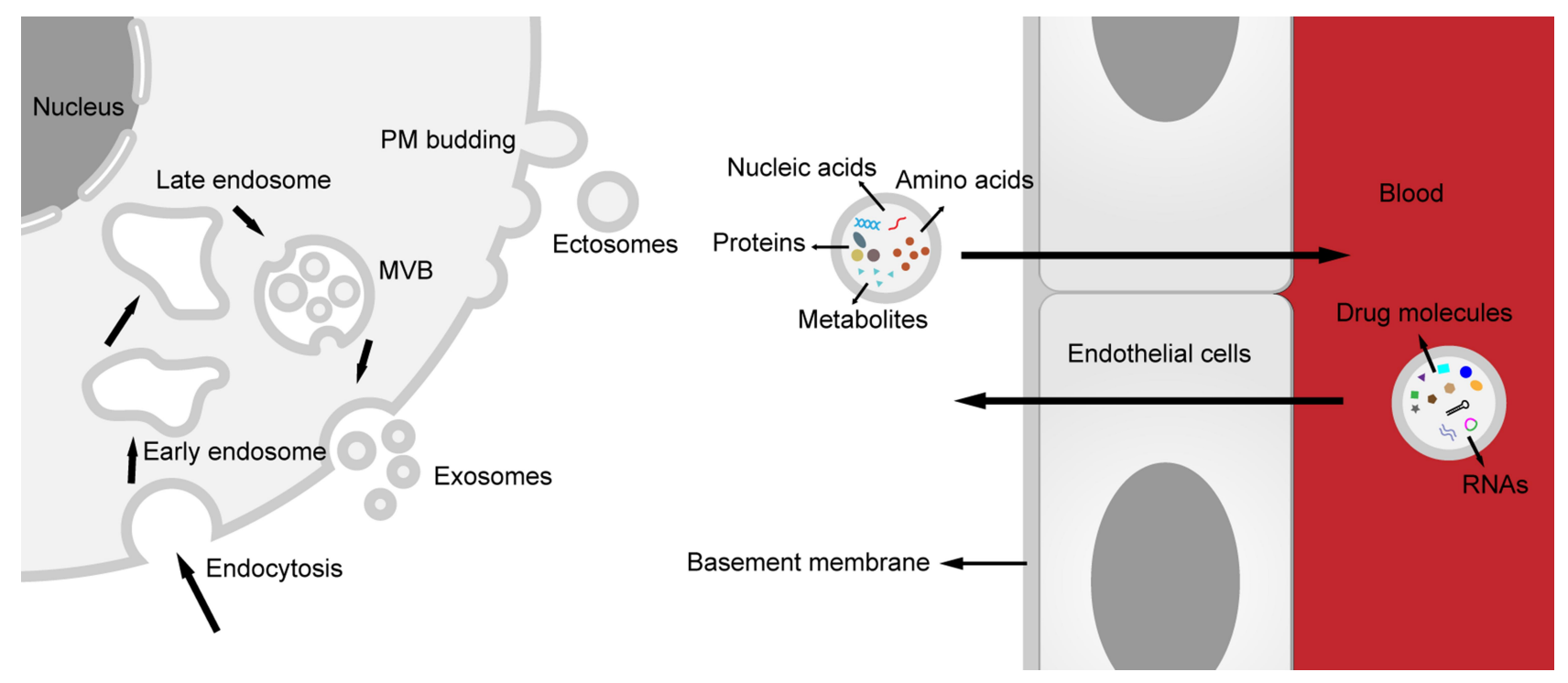

Figure I Biogenesis of extracellular vesicles (EVs) and transport across the blood-brain barrier (BBB). Two subtypes of EV, exosomes and ectosomes, represent two different biogenesis. Exosomes are derived from endosome pathway, while ectosomes are formed directly through plasma membrane budding. EVs can cross the BBB easily. On the one hand, various components, including nucleic acids, proteins, amino acids and metabolites in the EVs can be transported from the central nervous system (CNS) to peripheral biofluids, on the another, RNAs (including circular RNA, short hairpin RNA and small interfering RNA) and drug molecules (such as catalase, dopamine and Edaravone etc.) can be delivered to the CNS.

Abbreviations: MVB, multivesicular body; PM, plasma membrane. 
cytosolic components, altered in response to changes in the cell state, are the source of information and signals. The endosomal sorting complex required for transport assists in targeting cargo to exosomes, ${ }^{12}$ and members of the Rab family of small GTPases have an acknowledged role in trafficking vesicles intracellularly ${ }^{13}$ as well as a potential impact for exosome secretion. ${ }^{14}$ Soluble N-ethylmaleimide-sensitive fusion attachment protein receptor (SNARE) complexes are critical for MVB fusion with the PM, since the YKT6 SNARE has been proved to be necessary for Wnt-bearing exosomes secretion, ${ }^{15}$ and synaptosomal-associated protein 23 contributed to MVBPM fusion spontaneously in vitro. ${ }^{16}$ Meanwhile, cytoskeletal components, including actin, actomyosin and microtubule network also engaged in budding and releasing of EVs. ${ }^{17,18}$ However, these mechanisms are not specific for biogenesis of EVs, but also associated with other secretion events. After being released, EVs undergo short or longdistance journal. It was reported that functional proteins, mRNAs and miRNAs contained in EVs can be transferred without changing their biological activity. ${ }^{19-21}$ EVs can work directly at recipient cells surface, for example, cognate $\mathrm{T}$ cell receptors on $\mathrm{T}$ lymphocytes can be activated by EVs with major histocompatibility complex (MHC)-peptide complexes. ${ }^{22}$ Yet, in most cases, the contents of EV are effector molecules. Multiple mechanisms have been clarified in the uptake of EVs by recipient cells, such as micropinocytosis, direct fusion with the PM, and clathrindependent endocytosis. ${ }^{9}$ However, potential impacts caused by different modes on subsequent fate or functional outcomes of EV constituents are not clear. Proinflammatory cytokines mediated secretion of EVs with IFN $\gamma$-bound-IFN $\gamma$ receptor 1 from NPC can activate IFN $\gamma$ receptor 1 , signal transducer and activator of transcription 1 in recipient cells, ${ }^{23}$ indicating an inductive effect on targeting cells.

EVs are involved in antigen presentation in immune regulation. On the one hand, EVs with peptide(p)-MHC can be captured and laid in antigen presenting cells surface, and then p-MHC is presented to T cells directly. On the other hand, when EVs are taken in, their antigenpeptides are assembled into MHC molecules of the host antigen presenting cells, and this new p-MHC complexes will be presented to the T cells. ${ }^{24}$ In the field of oncology, EVs enrolled in initiation and promotion of tumor. Stefanius et al reported exosomes derived from pancreatic cancer cells can induce mutations in recipient cells, thus launch malignant cell transformation. ${ }^{25}$ EVs containing
miR-200, released by breast cancer cells, promote mesenchymal-to-epithelial transition in nonmetastatic cells or metastasis in weakly metastatic cells, ${ }^{26}$ indicating a role in plasticity of tumor cells. In breast cancer, exosomes containing miR-105 impair the integrity of blood vessels by inhibiting expression of zonular occludens 1 , a crucial endothelial tight junction protein, ${ }^{27}$ implying EVs are associated with tumor metastasis. Some EVs released by glioblastoma (GBM) express programmed death ligand-1 in the surface, and whose combination with programmed cell death protein- 1 can inhibit $T$ cell activation, and therefore, causing immune evasion. ${ }^{28}$

\section{Separation and Characterization of EVs}

EVs are collected from extracellular fluids, which means it is necessary to avoid contamination of vesicles originated from the intracellular compartments. Although an acknowledged and standardized isolation procedure is not available, various methods have been applied in different degree, including ultra-speed centrifugation, ultrafiltration, immunoaffinity capture, charge neutralization-based polymer precipitation, size-exclusion chromatograph, and microfluidic techniques. ${ }^{2}$ Among them, differential ultracentrifugation is still the most common approach to achieve separation and purification of EVs. ${ }^{29}$ Gradient ultracentrifugation, separating particles by different density, is used to eliminate contaminating non-vesicular particles, such as free proteins and protein-RNA complexes. ${ }^{30}$ Ultrafiltration is based on ultrafine Nano-membrane to isolate EV subtypes and may represent a more efficient and faster method when compared to the above two methods. $^{31}$ Immunoaffinity isolation is based on two key points: the presence of distinctive protein markers on EVs and antigen-antibody binding reaction, showing great superiority in separating unique EV populations. Polymeric precipitation and chromatograph have been utilized in commercial kits, such as ExoQuick and qEV. High yields may have been achieved with the former ${ }^{32}$ while the latter can protect EVs structure from mechanical damage. $^{33}$ These techniques are not mutually independent and sometimes a better choice may be a combination of two or three, based on research requirements and the feature of the tested sample.

After preliminary separation and enrichment, the next is $\mathrm{EV}$ characterization, which is the foundation of further functional studies. First step is the identification of EV protein markers. According to the recommendation of minimal information for studies of extracellular vesicles 
$2018,{ }^{1}$ three types of proteins have to be evaluated, including PM and/or endosomes related proteins, cytosolic/periplasmic proteins binding to lipid or membrane protein, and co-isolated contaminants related proteins. The second step is to characterize single vesicles. Transmission electron microscope provides visual evidence for the morphology, size and fine structure of single EV, and nanoparticle tracking analysis evaluates concentration and size distribution of EV populations. ${ }^{34,35}$ Of note, lipoprotein particles, protein complexes and other particles which, with a similar size, are difficult to distinguish from EVs through these two methods. Some other techniques, such as resistive pulse sensing, dynamic light scattering and flow cytometry, are also being developed and applied. ${ }^{34,36}$ In most cases, "exosomes" mentioned in the studies are actually a mixture of vesicles, therefore, the generic term "EVs" is applied in this review, while the term "exosomes" is also retained under some circumstances, in order to be consistent with the cited literature.

\section{The Content of EVs}

EVs contain a variety of bioactive molecules, including soluble proteins, DNA, RNA, lipids and metabolites. RNA is considered as the primary regulator of the activity of recipient cells and have aroused great enthusiasm and interest in the scientific community. Following are the brief introduction for two special types of RNA, both of them are research hotspots in recent years. Long noncoding RNA (lncRNA), a member of non-coding RNAs comprised of more than 200 nucleotides, acts as the regulator of gene expression at the translation level or epigenetic level by self-degradation and re-expression. ${ }^{37}$ It has been reported that EVs can play a role in disease regulation through lncRNA. For instance, IncRNA H19, delivered by exosomes, regulated endothelial cell phenotype and promoted angiogenesis in CD90+ hepatoma carcinoma cells. $^{38}$ Exosomal lncRNA KLF3-AS1 inhibited chondrocyte apoptosis, which was induced by IL-1, and promoted cartilage repair and cell proliferation in osteoarthritis rat models. $^{39}$

Circular RNA (circRNA) is a novel member of noncoding RNAs, with covalent closed-loop structure caused by back-spliced exons in nucleus. It was reported circRNAs are more abundant and stable in exosomes than in producer cells, ${ }^{40}$ implying the former might be major mediators for circRNAs functions. Synthesis of exosomal circRNAs is associated with the alteration of miRNAs level in parental cells and the correlation can be reflected dynamically in recipient cells, ${ }^{41}$ indicating a possible interaction mechanism between these two. It has been widely studied that circRNA act as "miRNA sponge", that is the former is competing endogenous RNA to bind miRNA, due to their enriched binding sites. $^{42,43}$ For example, cirNRIP1, which was transmitted by exosome and high expressed in gastric cancer, regulated the expression level of AKT1 by sponging miR-1495 p. Knocking down circNRIP1 resulted in inhibition of proliferation, migration and invasion of cancer cells. ${ }^{42}$ Zhang et al reported exosomal hsa_circ_0010522 (a circRNA bind to miR-133) promote white adipose browning in gastric cancer by PRDM16 and miR-133 pathways, offering insight into the molecular mechanism of cancer-related cachexia. ${ }^{44}$ Current studies showed the effect of circRNAs in cell proliferation, tumor metastasis and drug resistance of cancer. Tian et al discovered serum exosomal circRASSF2 is higher in laryngeal squamous cell carcinoma, while proliferation of malignant cells was suppressed by knocking down circRASSF2. This regulatory effect may be mediated through miR-302b-3p/insulinlike growth factor $-1 \mathrm{R}$ axis. ${ }^{45} \mathrm{Li}$ et al reported high circRNA PDE8A expression in exosomes secreted by pancreatic cancer cells are relevant to the invasive growth of tumor cells and lymphatic invasion via the miR-338/ MACC1/MET pathway. ${ }^{46}$ Expression of exosomal Friend leukemia virus integration 1 circRNAs are significantly higher in small cell lung cancer and related to clinical chemotherapy and poor survival, ${ }^{47}$ indicating a potential impact in drug resistance. Figure 1 is a simple illustration for EVs contents.

\section{The Uniqueness of EVs in the CNS}

Compared with peripheral organs, brain and spinal cord have their own specialty, and relatively, EVs play unique roles in the CNS. Neurogenesis, the process by which new neurons are formed in the brain, is crucial when an embryo is developing. In the adult mammalian brain, neurogenesis also continues in certain regions throughout lifespan. The structural basis is "neurogenic niche", composed of multiple cell types including NSCs/NPCs, neuroblasts, immature and mature neurons, while EV is an important chain to connect these cells, through their containing bioactive molecules. ${ }^{48}$ Exosomal miR-let7b and miR-9, expressed in NSCs/NPCs, are capable of regulating stem cell proliferation and differentiation by targeting nuclear receptor TLX $^{49,50}$ A reductionist experimental paradigm revealed that neuronal exosomes participate in development of 
neural circuits, covering cell proliferation, differentiation, synaptogenesis, and synchronized firing, which is mainly based on neurodevelopmental signaling proteins. The result was confirmed by proteomic analysis of components of two exosomes. ${ }^{51}$

EVs are involved in regulation of neuronal firing, synaptic plasticity, formation and maintenance of myelination, propagation of neuroinflammation, neuroprotection, and spread and clearance of toxic protein aggregates. ${ }^{52}$ Secretion of neuronal EVs is coupled to synaptic activity (neuronal depolarization or excitatory neurotransmitter release), suggesting EVs may be related to plasticityassociated processes. It has been recognized that the final effect of different frequencies of stimulation is the change in quantity of $\alpha$-amino-3-hydroxy-5-methyl-4-isoxazolepropionic acid receptors (AMPARs) in the postsynaptic membrane, ${ }^{53}$ while EVs can transport AMPARs activitydependently, prompting a potential mechanism for alteration of synaptic strength. ${ }^{54,55}$ In a study of the Drosophila neuromuscular junction, Korkut et al demonstrated that Wingless, a Wnt-family signaling protein, is shuttled on EVs across synaptic space, and the formation of synaptic boutons is suppressed as this EV-based trafficking is interrupted. $^{56,57}$ The activity-regulated cytoskeletonassociated protein, which is a crucial mediator for synaptic plasticity, self-assembly forms capsids like viral groupspecific antigen proteins and is transmitted intercellularly by EVs. Similarly, blocking this trafficking at the Drosophila neuromuscular junction impaired synapse maturation and activity-dependent plasticity. ${ }^{58}$ Furthermore, EVs were deemed to be engaging in synaptic pruning. Microglial cells participate in the removal of degenerating neurites of $\mathrm{PC} 12$ cells, and this phagocytosis can be promoted via pre-processing of exosomes, which were secreted by the differentiated PC12 cells, most likely due to the elevation of complement component $3 .^{59} \mathrm{In}$ neurodegenerative diseases, to some extent, roles of exosomes are paradoxical. On the one hand, exosomes exert a neuroprotective function, for they promote fibrillization of amyloid beta $(A \beta)$, in turn, the formation of oligomeric $A \beta$, eliciting neurotoxic effects in Alzheimer's disease (AD), is interrupted. ${ }^{60}$ Neuronal exosomes also contribute to capturing, clearing $A \beta$ in amyloid precursor protein transgenic mice. ${ }^{61}$ On the other hand, exosomes exert "pathogenicity". Asai et al observed that tau propagation is relieved in vitro and in vivo by inhibiting exosomes synthesis, which suggested a possible impact of exosomes for the progression of tauopathy. ${ }^{62}$ Similar phenomena were discovered in Parkinson's disease (PD) ${ }^{63}$ and amyotrophic lateral sclerosis (ALS) for their signature pathological proteins. ${ }^{64,65}$

\section{Applications of EVs in CNS Disease Neurodegenerative Diseases PD}

In PD, $\alpha$-synuclein ( $\alpha$-syn) is a well-known pathogenic protein, and its correlation with diagnosis and staging of disease has been investigated widely. A recent study reported that in the early stage of PD, $\alpha$-syn level is increased in plasma exosomes, yet the difference is not significant between idiopathic rapid eye movement sleep behavior disorder (RBD) and healthy groups. That means $\alpha$-syn can identify PD and RBD, since the latter often appear as an early nonmotor symptom of the former. More important, $\alpha$-syn level was positively correlated to the severity of PD. Similar phenomenon was observed that patients whose $\alpha$-syn longitudinally increased underwent deterioration of motor symptom in the follow-up. ${ }^{66}$ Some other studies confirmed the value of increased exosomal $\alpha$ syn, oligomeric $\alpha$-syn or the ratio of it to total $\alpha$-syn in different biological fluids as biomarkers of PD. ${ }^{67-69}$ Interestingly, $\mathrm{Si}$ et al reported $\alpha$-syn level in CNSderived exosomes is lower in PD patients than essential tremor and healthy groups. ${ }^{70}$ This result contradicting with the above studies, which may be interpreted as detected exosomes were L1CAM-labeled, a marker protein of the CNS, thus excluding contamination of $\alpha$-syn from peripheral tissues sources. Actually, exosomal $\alpha$-syn level in CSF was reported to be lower in PD group, due to increased efflux of $\alpha$-syn to the peripheral blood. ${ }^{71}$ Leucine-rich repeat kinase 2 (LRRK2) mutation is a widely acknowledged cause for inherited PD. In urine exosomes, autophosphorylated Ser(P)-1292 LRRK2 level was higher in PD patients than controls, and heralded poorer cognitive performance. ${ }^{72}$ Gui et al characterized exosomal miRNA profiles in CSF and uncovered 11 miRNAs levels were downregulated while 16 miRNAs levels were upregulated in PD group. Through further validation in independent samples, miR-1 and miR-19b-3p levels were decreased and miR-153, miR-409-3p, miR-10a-5p and let-7p-3p levels were increased significantly. Biological pathway analysis associated with these miRNAs revealed Neurotrophin signaling, mTOR signaling, Ubiquitin mediated proteolysis, Dopaminergic synapse and Glutamatergic synapse. ${ }^{73}$ More differentially expressed 
Table I Biomolecules Expressed Differentially in EVs Were Considered as Biomarker Candidates of Parkinson's Disease (PD)

\begin{tabular}{|c|c|c|c|c|c|c|}
\hline Down-Regulated & Up-Regulated & $\begin{array}{l}\text { ROC Curve } \\
\text { Analysis }\end{array}$ & Species & $\begin{array}{l}\text { Sample } \\
\text { Size }\end{array}$ & Specimens & Ref \\
\hline- & $\alpha-$ syn & Y & Human & $53 \mathrm{P}, 21 \mathrm{C}$ & Plasma & [66] \\
\hline- & DJ-I and $\alpha$-syn & Y & Human & $39 \mathrm{P}, 40 \mathrm{C}$ & Plasma & [67] \\
\hline- & $\alpha$-syn & Y & Human & $\begin{array}{l}275 P, 144 \\
C\end{array}$ & Serum & [68] \\
\hline- & $\alpha$-syn(Olig), $\alpha$-syn(Olig)/ $\alpha$-syn(Total) & Y & Human & $74 \mathrm{P}, 60 \mathrm{C}$ & Saliva & [69] \\
\hline$\alpha$-syn & - & Y & Human & $38 \mathrm{P}, 18 \mathrm{C}$ & Serum & [70] \\
\hline- & Ser(P)-I292 LRRK2 & $\mathrm{N}$ & Human & 79 P, 79 C & Urine & [72] \\
\hline miR-I, miR-19b-3p & $\begin{array}{l}m i R-153, \text { miR-409-3p, miR-10a-5p, and let- } \\
7 g-3 p\end{array}$ & Y & Human & 47P, $27 \mathrm{C}$ & CSF & [73] \\
\hline $\begin{array}{l}\text { Inc-MKRN2-42:I, Inc- } \\
\text { ZFAND5-29:1 etc }\end{array}$ & MSTRG.I44437.I, MSTRG. 16383.2 etc & $\mathrm{N}$ & Human & $32 \mathrm{P}, \mathrm{I} 3 \mathrm{C}$ & Plasma & [74] \\
\hline miR-19b & miR-195, miR-24 & Y & Human & $\begin{array}{l}109 P, 43 \\
C\end{array}$ & Serum & {$[168]$} \\
\hline miR-505 & miR-33I-5p & Y & Human & $52 \mathrm{P}, 48 \mathrm{C}$ & Plasma & {$[169]$} \\
\hline- & $\begin{array}{l}\text { let-7d, miR-22*, miR-23a, miR-24, miR-142- } \\
\text { 3p, and miR-222 }\end{array}$ & Y & Human & $30 \mathrm{P}, 30 \mathrm{C}$ & Serum & {$[170]$} \\
\hline
\end{tabular}

Notes: "*”" denotes miRNA with low expression level, which generate from an arm of the precursor. We mainly incorporated representative literatures in the last five years. Abbreviations: ROC, receiver operating characteristic curve; Ref, reference; $\alpha$-syn, alpha-synuclein; Y, yes; N, no; P, PD patients; C, healthy controls; Olig, oligomeric; LRRK2, leucine-rich repeat kinase 2; CSF, cerebrospinal fluid.

miRNAs in EVs in PD group are listed in Table 1. LncRNA level was evaluated in plasma exosomes collected from $\mathrm{PD}$ and healthy group by next-generation sequencing and real-time quantitative polymerase chain reaction. Among 39 dysregulated IncRNAs, lnc-MKRN2 $-42: 1$ level was positively correlated with Unified PD Rating Scale Part III score, indicating a value in predicting severity of motor symptoms. ${ }^{74}$

Applications of EVs in PD therapy is embodied in two aspects: one is administration of EVs derived from stem cells, and another is to design EVs as drug vehicles. It was reported intracerebral injection of bone marrow mesenchymal stem cell (MSC) secretome, containing various bioactive molecules and EVs, into substantia nigra pars compacta and striatum of 6-hydroxydopamine induced PD rat models, redound to rescue dopaminergic neurons and improve behavioral performance. ${ }^{75}$ The conclusion explained the paracrine mechanism of MSCs. Chen et al proposed that increased autophagy induced by exosomes may be potential mechanism of cytoprotection in 6-hydroxydopamine-stimulated SH-SY5Y cells. ${ }^{76}$ As a critical pathogenic pathway of PD, oxidative stress mediated by reactive oxygen species is also a promising therapeutic target. Haney et al exploited a novel drug delivery system based on exosomes, containing about $940 \pm 15$ catalase molecules in each of them. Catalase-exosomes significantly decreased reactive oxygen species levels in activated macrophages in vitro, while in a PD mice model, suppressed brain inflammation and increased neuronal survival, compared to free catalase only. As a contrast, exosomes without loading catalase showed little neurotoxicity. ${ }^{77}$ The similar idea was adopted by another study, which catalase mRNA was loaded into designer exosomes. ${ }^{78}$ Small interfering RNA (siRNA), a representative molecule of RNA interference, is composed of a guide strand and a passenger strand with 21-23mer in lengths. siRNAs bind to RNAinduced silencing complex to form typically RNA interference effector molecule, which efficiently downregulate gene expression by degrading mRNAs in posttranscription level. Cooper et al reported that intravenous injection of exosomes carrying $\alpha$-syn siRNAs reduce $\alpha$-syn mRNA level and intraneuronal misfolded protein aggregation. ${ }^{79}$ Short hairpin RNA (shRNA) is another common molecular tool to regulate expression level of genes. 
RVG (rabies virus glycoprotein peptide)-exosomes loading with $\alpha$-syn shRNA minicircles were applied to PD mice model, resulting in alleviation of $\alpha$-syn aggregation. Downregulation of $\alpha$-syn gene under experimental condition had no negative consequences for normal neural functions. ${ }^{80}$ Dopamine replacement is the core of current drug therapy for PD, while dopamine cannot cross the blood-brain barrier (BBB). In consequence, Qu et al developed a blood exosome-based delivery system with dopamine loaded efficiently, and reported systemic administration of designer exosomes improve symptomatic performance in a PD mouse model. Though exosomes can be detected in non-lesional brain area (hippocampus) or peripheral organs, no significant histopathological changes and functional impairment were observed, except renal mesangiolysis. ${ }^{81}$ More information is offered in Table 2.

\section{AD}

Since tau and $A \beta$ are most representative pathogenic proteins of $\mathrm{AD}$, their roles in diagnosis and prognosis have also aroused the attention from researchers. A recent study demonstrated levels of exosomal phosphorylated (p)-S396 -tau and A $31-42$ are significantly higher in plasma of $A D$ patients. Concomitantly, smaller and fewer exosomes were observed in $\mathrm{AD}$ group. ${ }^{82}$ Dynamic changes in abnormal protein levels during $\mathrm{AD}$ progress were explored by another study. Nam et al discovered total (t)-tau and p-tau levels in neuron-derived exosomes of serum are significantly higher in mild-AD group than mild cognitive impairment group. Levels of these two proteins were positively correlated with neuropathological progression and symptom severity. ${ }^{83}$ Interestingly, these signature proteins were also explored in Down syndrome (DS), which present $\mathrm{AD}$ pathologic changes in the brain as well as cognitive impairment or dementia in early life. Hamlett et al found increased levels of Aß1-42, p-t181-tau and p-S396-tau in neuronal exosomes in DS group compared to HC. The discovery was consistent across all age groups, implying dysregulated protein expression may start in birth and gradually accumulate over time. $^{84}$ In a following review, the author concluded exosome secretion is increased in the DS brain, which might be a compensatory mechanism to remove excess toxic amyloid protein intracellularly. ${ }^{85}$ Jain et al identified a combination of small noncoding RNAs-three miRNAs and three piwi-interacting RNAs, which shows surprising capability of detecting $\mathrm{AD}$ and predicting the conversion of mild cognitive impairment patients to $\mathrm{AD}$ dementia. ${ }^{86}$ The treatment of AD remains a huge challenge, nonetheless a few small advancements have been realized in basic science research. Yang et al demonstrated exosomes

Table 2 Applications of EVs in the Therapy of Parkinson's Disease (PD)

\begin{tabular}{|c|c|c|c|c|c|c|}
\hline Agents & Vehicle & Species & Route & In vitro & Effects & Ref \\
\hline- & $\begin{array}{l}\text { BMSCs } \\
\text { secretome }\end{array}$ & Rats & $\begin{array}{l}\text { intracerebral } \\
\text { injection }\end{array}$ & Y & $\uparrow$ behavioral performance, rescue dopaminergic neurons & [75] \\
\hline- & $\begin{array}{l}\text { Human } \\
\text { umbilical cord } \\
\text { MSCs Exo }\end{array}$ & Rats & IV & Y & $\begin{array}{l}\downarrow \text { apomorphine-induced asymmetric rotation, } \\
\downarrow \text { dopaminergic neuron loss and apoptosis, } \uparrow D A \text { in the } \\
\text { striatum }\end{array}$ & [76] \\
\hline Catalase & Exo & Mouse & $\begin{array}{l}\text { intranasal } \\
\text { administration }\end{array}$ & Y & $\downarrow$ brain inflammation, $\uparrow$ neuronal survival & [77] \\
\hline $\begin{array}{l}\text { Catalase } \\
\text { mRNA }\end{array}$ & Designer Exo & Mice & $\begin{array}{l}\text { subcutaneous } \\
\text { transplantation }\end{array}$ & Y & $\downarrow$ neurotoxicity, $\downarrow$ neuroinflammation & [78] \\
\hline$\alpha$-syn siRNA & RVG-Exo & Mice & IV & $\mathrm{N}$ & $\downarrow$ intraneuronal protein aggregation & [79] \\
\hline $\begin{array}{l}\text { Anti- } \alpha \text {-syn } \\
\text { shRNA } \\
\text { minicircles }\end{array}$ & RVG-exosomes & Mice & IV & Y & $\begin{array}{l}\downarrow \alpha \text {-syn aggregation, } \downarrow \text { loss of dopaminergic neurons, } \\
\uparrow \text { clinical symptoms }\end{array}$ & [80] \\
\hline DA & Blood Exo & Mouse & IV & Y & $\uparrow$ symptomatic performance, $\downarrow$ systemic toxicity & [81] \\
\hline
\end{tabular}

Notes: We mainly incorporated representative literatures in the last five years.

Abbreviations: Ref, reference; BMSC, bone marrow mesenchymal stem cell; Y, yes; N, no; “个”, improve; “ ””, exacerbate; IV, intravenous injection; MSC, mesenchymal stem cell; Exo, exosomes; DA, dopamine; EVs, extracellular vesicles; $\alpha$-syn, alpha-synuclein; siRNA, small interfering RNA; RVG, rabies virus glycoprotein peptide; shRNA, short hairpin RNA. 
collected from human umbilical cord MSCs could decrease $\mathrm{A} \beta$ production by regulating $\alpha / \beta$-secretase expression levels. In AD mice model, administration of exosomes improved memory and cognitive function. ${ }^{87}$ Nakano et al verified miR-146a transferred by bone marrow MSC derived-exosomes could decrease NF-kappaB level, which might rescue astrocytic function and promote synaptogenesis, eventually, ameliorate cognitive impairment. $^{88}$ Targeting the tau pathology, exosomes loaded with curcumin and quercetin were designed to alleviate the AD symptoms both through inhibiting hyperphosphorylation of tau, while upstream mechanisms were different. ${ }^{89,90}$

\section{ALS}

In ALS, proteomic analysis was conducted by some researchers aiming to screen potential biomarkers. Through detecting exosome-enriched fractions of CSF of ALS patients, 14 dysregulated proteins were identified, among which level of novel INHAT repressor shows the maximum increase. ${ }^{91}$ Thompson et al analyzed protein profiles of CSF EVs from ALS and control groups, and found significant decreased levels of pentameric proteasome-like protein Bleomycin hydrolase and proteasome core complex protein. Whilst Ubiquitin-like modifying-activating protein 1 were upregulated in ALS patients associated with hexanucleotide repeat expansion in C9orf72, hinting the ability to identify different disease subtypes. ${ }^{92}$ For the alteration of miRNA levels in CSF EVs, Katsu et al reported 30 differentiated miRNAs, which are mainly involved in synaptic vesicle-related pathways by target gene analysis. ${ }^{93}$ Saucier et al revealed a miRNAs signature of plasma EVs in ALS and healthy groups, comprising 5 upregulated miRNAs and 22 downregulated miRNAs. Diagnostic potential of miR-15a-5p was validated for ALS, while miR-193a-5p was relevant to disability progression. $^{94}$ In general, ALS is a progressive, fatal disease without any potent treatment, however, some researchers tried to explore possible disease-modifying therapies. In 2016, Lee et al demonstrated adipose-derived stem cell (ASC) exosomes can mediate improvement of superoxide dismutase 1 aggregation and mitochondrial dysfunction in vitro. ${ }^{95}$ The role of ASC was validated in some other studies. Bonafede et al reported the anti-apoptotic effect of ASC-exosomes in an ALS cell model, supported by increasing of antiapoptotic protein and decreasing of pro-apoptotic proteins through proteomic analysis of exosomes. ${ }^{96}$
Furthermore, neuroprotective effect of ASC-exosomes was confirmed in superoxide dismutase 1 (G93A) murine model. ${ }^{97}$

\section{Dementia with Lewy Bodies (DLB)}

DLB, one of the main cause of dementia just following $\mathrm{AD},{ }^{98}$ is often misdiagnosed owing to some resembling pathological features, such as tau deposits and $A \beta$ plaques. ${ }^{99,100}$ Gamez-Valero et al characterized protein profiles of plasma EVs between DLB and healthy groups, and identified differentially expressed gelsolin and butyrylcholinesterase. More important, in a further validation, gelsolin level decreased in DLB group compared to AD group. ${ }^{101}$ The team also described miRNA profiles of plasma EVs in these three groups, and revealed hsa-miR -451a and hsa-miR-21-5p levels significantly increase in DLB group compared to AD group, suggesting a potential of discriminating these two diseases. ${ }^{102}$ Currently, studies on DLB are few or just be affiliated to $\mathrm{AD}$ and $\mathrm{PD}$ research, more attention on DLB is to be expected in the future.

\section{Cerebrovascular Disease and Traumatic Disease of the CNS \\ Stroke}

Diagnosis of stroke depends on the medical history, clinical manifestations and especially neuroimaging changes. Though some studies have reported the alteration of exosomal molecules in blood samples from ischemic stroke (IS) patients compared to healthy controls (HCs), such as upregulated miR-223, ${ }^{103}$ miR-9, miR-124 ${ }^{104}$ and inflammasome protein, ${ }^{105}$ the relationship between exosomes and poor outcomes (higher National Institutes of Health Stroke Scale scores, larger infarct volumes or levels of inflammatory mediators) has also been explored. A mainstream view is apt to screen biomarkers of subtype identification and prognostic assessments. Classifying subtypes of IS, including cardioembolism, large artery atherosclerosis, lacunar infarct, and stroke of undetermined etiology, is important for individualized treatment and prevention strategies. A recent study detected expression levels of serum miRNA among these IS subtypes and identified miR-125b, miR-125a, let-7b, and let-7e are upregulated significantly in cardioembolism, but not in the other three subtypes compared to HCs. While compared to cardioembolism and HCs, miR-7-2-3p increased, and miR-1908 decreased significantly in these three 
subtypes. $^{106}$ It can be speculated that differentiated miRNAs are involved in pathogenesis of different subtypes. Kalani et al analyzed profiles of miRNA in plasma EVs from spontaneous intraparenchymal hemorrhage, aneurysmal subarachnoid hemorrhage and IS patients, and found 25 miRNAs classifiers with high accuracy in distinguishing three stroke subtypes. ${ }^{107}$ In animal models and IS patients, Chi et al observed increased expression of Fas gene, as well as regulated miRNAs- hsa-let-7b-5p in plasma, are related to hyperglycemia after acute stroke onset, which often predicts an unfavorable outcome. Higher Fas expression was verified in exosomes. These two biomarkers may be candidate risk factors, pointing to poor neurological outcomes when combined with other traditional risk factors. ${ }^{108}$

The therapy of stroke is unmet, since the time window for effective treatment (such as intravenous thrombolysis or mechanical thrombectomy) is narrow and few drugs are available or their efficacy is not widely recognized. Doeppner et al verified the curative effect of MSC-EVs is not inferior to MSCs transplantation in a mice IS model. ${ }^{109}$ In a subcortical stroke model, intravenous injection of MSC-EVs restored white matter integrity, which was measured by fiber tract integrity and axonal sprouting. ${ }^{110}$ Moon et al reported MSC-EVs are mainly assembled in the infarcted hemisphere, not in the lung and liver, indicating a favorable lesion tropism. Moreover, biomolecules showing efficacy in EVs were investigatedthat were miR-184 and miR-210. ${ }^{111}$ As previously mentioned, NSCs/NPCs are critical participants in neurogenesis, the role in post-stroke neural restoration has also been elucidated. Webb et al evaluated the effect of NSC-EVs in a porcine IS model. Three doses within 24 hours after stroke provoked a range of pathologic and symptomatic improvements (less lesion volume and brain swelling, better behavior and mobility). ${ }^{112}$ In a rodent model, NPCEVs administration was identified as improving neurological recovery and neuroregeneration, lasting for three months. ${ }^{113}$ Treatment of EVs derived from human cardiosphere-derived cell in a rabbit model did not increase the risk of intracerebral hemorrhage $(\mathrm{ICH})$ or decrease survival rate, and is even better than rt-PA in attenuating behavioral deficits. ${ }^{114}$ Microglia activation within minutes of cerebral ischemia, ${ }^{115}$ release of pro-inflammatory and neurotoxic factors like IL- $1 \beta$, TNF- $\alpha$, IFN- $\gamma$, and triggering of cerebral inflammation are significant cascade reactions, ${ }^{116}$ in addition to direct ischemia attack after stroke. Microglia have two phenotypes-M1 initiates and aggravates inflammation response, yet M2 does the opposite. ${ }^{117}$ It has been proved that exosomes secreted by lipopolysaccharide-stimulated macrophage regulate neuroinflammation by promoting microglial polarization from the M1 to the M2. ${ }^{118}$ Likewise, it's a reasonable speculation that EVs derived from M2 phenotype comprise anti-inflammatory bioactive molecules. A recent study reported M2 microglia-derived exosomes reduce neuronal apoptosis and infarct volume, and improve behavioral performance in vitro and in vivo. MiR-124 was regarded as a major contributor, as neuroprotective effect was weaker after being knocked down. ${ }^{119}$ Definitely, a more effective method is to load molecules of interest into exosomes with the ability to target the brain. Tian et al designed the $\mathrm{c}(\mathrm{RGDyK})$ peptide-conjugated exosomes with curcumin loaded, which exhibit superior performance in targeting ischemic lesions and inhibiting inflammatory response. $^{120}$ Two studies employed RVG-exosomes and macrophage-derived exosomes to deliver nerve growth factor (protein and mRNA) and Edaravone, respectively, and both observed the effect of anti-inflammation and neuroprotection. ${ }^{121,122}$ Exosomes increased the utility of Edaravone compared to the dissociative state. Application value of some miRNAs, including miR-17-92 cluster, miR-210, miR-126 delivered by EVs has also been reported in rodent stroke models. ${ }^{123-125}$ Noteworthily, there was a study that explored the role of circRNA in both mice and nonhuman primate IS models. As a typical endogenous non-coding RNA molecule, the function of circRNA is still elusive. Yang et al engineered RVG-EVs loading with circSCMH1, produced from the Scm Polycomb Group Protein Homolog 1 gene, which was screened by their preliminary study that circSCMH1 levels are significantly downregulated in the plasma of IS group. Administration of exosomes offered a remarkable brain protective effect. ${ }^{126}$ EVs application in the treatment of stroke is summarized in Table 3. More promising agents would be exploited to improve functional outcomes of IS through combining with EV vehicles.

\section{Traumatic Brain Injury (TBI) and ICH}

TBI, often caused by traffic accidents and unintentional falls, result in long-term neurological impairments and even death. CT and MRI are conventional tools to evaluate TBI, however, sometimes are insufficient for mild injuries or cannot provide more prognostic information. ${ }^{127}$ Some 
Table 3 Applications of EVs in the Therapy of Stroke

\begin{tabular}{|c|c|c|c|c|c|}
\hline Agents & Vehicle & Species & In vitro & Effects & Ref \\
\hline- & MSC-EVs & $\begin{array}{l}\text { C57BL6 } \\
\text { mice }\end{array}$ & $\mathrm{N}$ & $\begin{array}{l}\downarrow \text { neurological impairment, } \uparrow \text { angio- neurogenesis, } \\
\downarrow \text { immunosuppression }\end{array}$ & {$[109]$} \\
\hline- & MSC-EVs & Rats & $\mathrm{N}$ & $\begin{array}{l}\uparrow \text { functional recovery, fiber tract integrity, axonal sprouting and white } \\
\text { matter repair markers }\end{array}$ & {$[110]$} \\
\hline- & MSC-Exo & Rats & $\mathrm{N}$ & $\uparrow$ neurogenesis, angiogenesis, behavioral performance & {$[111]$} \\
\hline- & NSC-EVs & Pig & $\mathrm{N}$ & $\begin{array}{l}\downarrow \text { cerebral lesion volume and brain swelling, } \uparrow \text { white matter integrity, } \\
\uparrow \text { behavior and mobility }\end{array}$ & {$[112]$} \\
\hline- & NPC-EVs & $\begin{array}{l}\text { C57BL6 } \\
\text { mice }\end{array}$ & $\mathrm{N}$ & $\uparrow$ neurological recovery and neuroregeneration & [113] \\
\hline- & Human CDC EVs & Rabbits & $\mathrm{N}$ & $\downarrow$ behavioral deficits & {$[114]$} \\
\hline- & $\begin{array}{l}\text { LPS-stimulated } \\
\text { macrophages Exo }\end{array}$ & Rats & Y & $\downarrow$ brain infarct volume, inflammation response & [118] \\
\hline- & $\begin{array}{l}\text { M2 microglia- } \\
\text { derived Exo }\end{array}$ & Mouse & $\mathrm{N}$ & $\downarrow$ neuronal apoptosis, infarct volume, behavioral deficits & [119] \\
\hline Curcumin & cRGD-Exo & Mice & $\mathrm{N}$ & $\downarrow$ inflammatory response and cellular apoptosis & {$[120]$} \\
\hline $\begin{array}{l}\text { NGF mRNA } \\
\text { and protein }\end{array}$ & RVG-Exo & $\begin{array}{l}\mathrm{C} 56 \mathrm{BL} / 6 \\
\text { mice }\end{array}$ & $\mathrm{N}$ & $\downarrow$ inflammation, $\uparrow$ cell survival, population of neuroblast & {$[12 \mid]$} \\
\hline Edaravone & $\begin{array}{l}\text { Macrophage- } \\
\text { derived Exo }\end{array}$ & Rat & $\mathrm{N}$ & $\begin{array}{l}\downarrow \text { the death of neuronal cells, } \uparrow \text { the polarization of microglia from } M I \text { to } \\
\text { M2 }\end{array}$ & [122] \\
\hline $\begin{array}{l}\text { miR-17-92 } \\
\text { cluster }\end{array}$ & Exo & Rats & $\mathrm{N}$ & $\begin{array}{l}\uparrow \text { neurological function, oligodendrogenesis, neurogenesis, and neurite } \\
\text { remodeling/neuronal dendrite plasticity }\end{array}$ & [123] \\
\hline $\operatorname{miR}-210$ & cRGD-Exo & Mouse & $\mathrm{N}$ & $\uparrow$ angiogenesis, animal survival rate & {$[124]$} \\
\hline miR-I26 & $\begin{array}{l}\text { Endothelial cells } \\
\text { Exo }\end{array}$ & Mice & Y & $\begin{array}{l}\uparrow \text { neurological and cognitive function, } \uparrow \text { axon density, myelin density, } \\
\text { vascular density, arterial diameter, }\end{array}$ & {$[125]$} \\
\hline $\begin{array}{l}\text { Circular RNA } \\
\text { SCMHI }\end{array}$ & RVG-EVs & $\begin{array}{l}\text { Mice, } \\
\text { monkeys }\end{array}$ & $\mathrm{N}$ & $\begin{array}{l}\uparrow \text { functional recovery, neuronal plasticity, } \downarrow \text { glial activation and } \\
\text { peripheral immune cell infiltration }\end{array}$ & [126] \\
\hline
\end{tabular}

Notes: We mainly incorporated representative literatures in the last five years. In all studies, EVs or exosomes were injected intravenously.

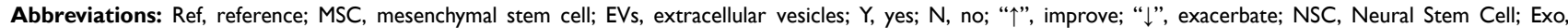
exosomes; NPC, neural progenitor cells; CDC, cardiosphere-derived cell; LPS, lipopolysaccharide; cRGD, c(RGDyK)-conjugated peptide; NGF, nerve growth factor; RVG, rabies virus glycoprotein peptide; SCMHI, Scm Polycomb Group Protein Homolog I gene.

known TBI biomarkers, including aII-spectrin breakdown products, GFAP and its breakdown products, and UCH-L1 were higher in CSF exosomes from TBI group than control samples. ${ }^{128}$ Cheng et al characterized genetic profiles of salivary EVs in mild TBI and healthy groups, and confirmed the differential expression between two groups. Three genes-CDC2, CSNK1A1 and CTSD were upregulated, implying they might be involved in regulating the pathophysiological processes of TBI. ${ }^{129}$ In plasma exosomes of TBI rat models, 31 miRNAs were upregulated and 19 miRNAs were downregulated. Further pathway analysis suggested MAPK signaling pathway and Ras signaling pathway are related to the differentially expressed miRNAs. ${ }^{130}$ A study incorporating 196 veterans suggested increased level of neurofilament light chain in exosomes, which is correlated with repetitive mild TBI as well as chronic symptoms including postconcussive syndrome, posttraumatic stress disorder, and depression. This study showed neurofilament light might be a biomarker that predict remote outcomes after mild TBI. In 
a Yorkshire swine model subjected to TBI and hemorrhagic shock, early single-dose administration (after one hour of shock) of MSC-exosomes contributed to relieving brain swelling, reducing lesion size, and maintaining BBB integrity. ${ }^{131}$ Except for the early effects (6-hours), impact on late survival (7-days) was also observed - that is neurologic severity scores decrease significantly, accompanied by favorable neurologic recovery. ${ }^{132} \mathrm{Kim}$ et al reported intravenous injection of MSC-EVs into TBI mice timely (1h after modeling) rescue cognitive impairments. ${ }^{133}$ Post-repetitive mild TBI neurodegeneration and cognitive impairment has also been noticed, with miR-124-3p in microglial exosomes was considered as the main effector molecule by regulating Rela/ApoE signaling pathway. ${ }^{134}$ Secondary neuroinflammation is another significant pathologic process, inducing acute and chronic neurologic deficits. In 2017, Li et al demonstrated the ability of odontogenic stem cell derived exosomes to shift microglia M1/M2 polarization. ${ }^{135}$

\section{Spinal Cord Injury (SCI)}

In subacute SCI rats, serum exosomal miRNA profiles were accomplished, and a series of dysregulated miRNAs were identified. Especially 16 miRNAs, such as miR-485, miR-30b, and miR-26b were consistent with reported miRNAs in the circulation, which means these molecules are related to the pathological processes. ${ }^{136}$ In a SCI rat model, intravenous injection of MSC-EVs (instantly after attack and $24 \mathrm{~h}$ later) showed an anti-inflammatory effect, yet the possible mechanism is interaction of EVs with activated primary microglia, thus inhibiting proinflammatory cytokine (IL-1 $\beta$, IL-6) expression. ${ }^{137}$ Research has shown that phosphatase and tensin homolog (PTEN) can negatively regulate neuronal regeneration, which can be suppressed by retinoic acid receptor $\beta .^{138}$ Aiming at this target, MSC-exosomes loaded with PTEN siRNAs were given intranasally, exerting effects of promoting axonal growth and neovascularization, as well as alleviating microgliosis and astrogliosis. ${ }^{139}$ PTEN pseudogene 1 shRNA delivered by exosomes has been shown to ameliorate functional outcomes by targeting miR-21 and miR-19b. ${ }^{140}$ Two other studies have also validated the miR-21/miR19b/PTEN pathways. ${ }^{141,142}$

\section{Immune-Mediated Demyelinating Disease}

Demyelination disease is a generic term of heterogeneous diseases with different etiologies and manifestations, yet immune mediation is an important cause. He et al detected exosomal circRNA profiles in CSF samples from immunemediated demyelinating disease patients and controls, and identified 26 circRNAs differentially expressed. Among them, hsa_circ_0087862 and hsa_circ_0012077 showed the highest diagnostic accuracy for the disease. ${ }^{143}$ Multiple sclerosis (MS) is an autoimmune disease of the CNS, characterized by chronic inflammation and consequent demyelination of axons in different regions. ${ }^{144}$ It is meaningful to distinguish different subtypes. In 2017, one study incorporating 14 relapsing-remitting MS (RRMS), 11 primary-progressive/secondary-progressive MS patients and 11 controls, has detected miRNA levels in serum exosomes. The results indicated that 4 miRNAs (miR15b-5p, miR-30b-5p, miR-342-3p, and miR-451a) are significantly higher in RRMS patients and 6 miRNAs (miR370-3p, miR-409-3p, miR-432-5p, miR-15b-5p, miR223$3 \mathrm{p}$, and miR-23a-3p) increased in primary-progressive/secondary-progressive MS patients. Further analysis showed a high accuracy of 3 miRNAs (miR-433-3p, miR-432-5p, and miR-485-5p) in distinguishing RRMS from primaryprogressive/secondary-progressive MS patients. ${ }^{145}$ Another research recruited 63 RRMS patients and 32 controls, and revealed a combination of miR-122-5p and miR$196 \mathrm{~b}-5 \mathrm{p}$, both detected from serum exosomes, has advantage on differentiating relapse from remission in RRMS. ${ }^{146}$ Pharmacotherapy also alters exosomal miRNAs, which in turn, is a reflection of individual's response to the drug. A study revealed the dysregulated miRNAs including two upregulated and fourteen downregulated miRNAs in IFN- $\beta$-treated RRMS group compared to treatment-naïve group. ${ }^{147}$ In RRMS patients treated with fingolimod, disease activity can be predicted by using differentially expressed exosomal miRNAs. Ebrahimkhani et al found a combination of 2 or 3 miRNAs can distinguish active and quiescent status. ${ }^{148}$ In aquaporin-4 antibody serum-positive neuromyelitis optica spectrum disorders (NMOSD) patients, discrepant exosomal miRNA profiles helped identify NMOSD and HCs. In addition, upregulated hsa-miR-122-3p and hsamiR-200a-5p were valuable biomarkers to distinguish relapsing from remitting NMOSD, as well as indicate a more serious disease. ${ }^{149}$ Casella et al developed microglia-derived EVs with overexpressed Lactadherin (Mfge8) on the surface, aiming to target to phagocytes. Injection of IL-4 loaded EVs showed a significant antiinflammatory effect by upregulating chitinase 3-like 3 and arginase-1. ${ }^{150}$ Clark et al demonstrated increased myelination in MS animal models after MSC-EVs injection, which 
was achieved by promoting myelinating oligodendrocytes maturation. ${ }^{151}$ Administration of exosomes coupling to LJM-3064 aptamer, a remyelination inductive agent, can promote oligodendrocytes proliferation and inhibit inflammatory response, covering two of the most important targets of MS therapy. ${ }^{152}$

\section{Brain Tumors}

Liquid biopsy is a burgeoning field recently, referring to detection of tumor-derived biomarkers, including circulating tumor DNAs and RNAs, circulating tumor cells and EVs in collected biological fluids, such as blood and CSF. ${ }^{153}$ CSF-derived EVs are feasible sources of biomarkers for brain tumors, for direct biopsies are not practical in the early stages of the disease. Epidermal growth factor receptor variant III (EGFRvIII) mutation is considered as a common genetic alteration in GBM. Expression level of EGFRvIII RNAs was compared between resected tumor tissue and CSF-derived EVs, respectively. With sensitivity of $61 \%$ and specificity of $98 \%$, EGFRvIII RNAs positively kept consistent in both of these two groups. ${ }^{154}$ As a result, RNA signatures contained in CSF-derived EVs reflect the change of gene expression, and contribute to detecting genotypes of GBM. In plasma EVs obtained from GBM patients, miR-21 level was found to be significantly elevated. ${ }^{155}$ Compared to controls, the expression level of serum exosomal miR-301a in glioma patients increased, and was positively correlated with pathological grades. After surgical resection, miR-301a level went down. ${ }^{156}$ Hence, miRNAs in EVs are markers of disease stage and predict response to treatment. Fatty acid synthase, a key lipogenic enzyme overexpressed in GBM tissues, can be detected in plasma CD63+/CD81+ EVs from $75 \%$ of patients while cannot be detected in healthy group. The similar expression tendency was observed in glioblastoma cell lines and EVs isolated from conditioned medium. ${ }^{157}$ In a group incorporating 21 glioma patients, IDH1G396A mutation, which is an essential biomarker in human glioma, was checked out from peripheral blood EVs in $47.6 \%$ of the samples, through fast ColdPCR. ${ }^{158}$ With methods of size exclusion chromatography isolation and ultrasensitive immunoprofiling, syndecan-1 was first identified in plasma EVs from a glioma group, which can distinguish GBM from low-grade glioma. More important, after surgery, syndecan-1 expression reduced, meaning a role of monitor glioma progression. ${ }^{159}$ Though remarkable results have been achieved, some problems cannot be ignored. In clinical practice, acquiring CSF is time- consuming and invasive, yet plasma or serum samples is more convenient. However, complex and heterogeneous EV subtypes exist in blood. It was reported that a considerable proportion of EVs in the blood are plateletderived, ${ }^{160}$ as a consequence, enrichment of brain-derived EVs is necessary for further research.

\section{Epilepsy}

Temporal lobe epilepsy (TLE) occupied about $30 \%$ of total epilepsy, often accompanied by destruction of brain structure, emotional and cognitive impairment. Status epilepticus (SE) is a fatal condition with poor prognosis. ${ }^{161}$ One research depicted miRNA profiles in CSF-EVs and identified three upregulated miRNAs (miR-19b-3p, miR-21-5p, and miR-451a) in TLE and SE, as well as one downregulated miRNA (miR-204-5p) in SE group. These miRNAs were exceedingly accurate at distinguishing TLE or SE from other neurological disorders, supported by a high area under the curve value. ${ }^{162}$ Yan et al reported expression levels of miR-3613-5p and miR-6511b are significantly elevated, while 48 miRNAs are downregulated in plasma EVs, which was collected from 40 patients with mesial TLE with hippocampal sclerosis. Among 48 miRNAs, 6 miRNAs were regarded as involved in seizure development in mesial TLE with hippocampal sclerosis, yet miR-8071 was particularly prominent for its favorable sensitivity and specificity. ${ }^{163}$ One study screening protein biomarkers conducted both in mouse models and clinical samples indicated coagulation factor IX and thrombospondin-1 have great potential to distinguish epilepsy from HCs. ${ }^{164}$

Major brain impairments caused by SE are neurodegeneration and acute neuroinflammation, which might progress to chronic neuroinflammation or lead to the occurrence of spontaneous seizures. ${ }^{165}$ It has been verified that in animal models, "cytokine storm", which refer to a significant elevation of multiple proinflammatory cytokines and chemokines, is responsible for the acute inflammation in the hippocampus after SE. ${ }^{166,167}$ Long et al demonstrated intranasal administration of MSC-EVs in a mouse pilocarpine model alleviates "cytokine storm" and exerts remarkable neuroprotection. Besides, the extent of neurogenesis, especially for the reelin+ interneurons was preserved. ${ }^{167}$ Impact of MSC-EVs on SE or long term (6-8 months) functional outcomes of the brain remains to be investigated. 


\section{Conclusion}

The organism is a complex and complicated system, and the coordination of different components depends on efficient and timely exchange of materials and information. The traditional neuro-immuno-endocrine network has established the main framework for intercellular communication, but EVs have been considered as an important supplement. As the carrier of maternal cell information, the role of EVs in delivering molecules and signals has been widely recognized. Nevertheless, the effect reflected in the pathophysiology of the disease remains to be elucidated. More work is needed to understand whether EVs play a positive or negative role under different conditions during the occurrence and development of diseases. Among the many research related to EVs, the CNS diseases are a particularly popular field. Due to the presence of the skull, spine, BBB and blood-spinal cord barrier, it is less convenient to study the brain and spinal cord in vivo compared to other peripheral organs. The property of EVs that can freely enter and exit CNS, is the foundation of their application in diagnosis and treatment for CNS diseases. When we are intoxicated with the rosy prospect of EVs applied research, some common issues should also be taken into consideration. One is the selection of test samples, for CSF has always been considered an excellent "warehouse" of CNS biomarkers, but contamination of EVs from peripheral tissue cannot be excluded. Though readily available, the source of EVs in peripheral biofluids is complex, increasing the cost of technology for screening CNS origin. Another is the longterm safety assessment of EVs application in the treatment of CNS diseases. Identifying all the biomolecules in EVs, as well as their signalling pathways remains a huge challenge, which means in addition to the therapeutic effects that we observed, some potential adverse side effects may be omitted (such as carcinogenesis caused by transferring of oncogenes). Further and indepth research on EVs related to CNS diseases will help to better understand pathogenesis and accelerate potential clinical benefit.

\section{Abbreviations}

NSC, neural stem cell; NPC, neural progenitor cell; BBB, blood-brain barrier; PM, plasma membrane; MVB, multivesicular body; EGFRvIII, epidermal growth factor receptor variant III; SNARE, soluble N-ethylmaleimide-sensitive fusion attachment protein receptor; $\mathrm{MHC}$, major histocompatibility complex; AMPAR, $\alpha$-amino-3-hydroxy5-methyl-4-isoxazolepropionic acid receptor; $A \beta$, amyloid beta; $\alpha$-syn, $\alpha$-synuclein; LRRK2, leucine-rich repeat kinase 2; RVG, rabies virus glycoprotein peptide; ASC, adiposederived stem cell; PTEN, phosphatase and tensin homolog.

\section{Acknowledgments}

This research was funded by Zhejiang Provincial Natural Science Foundation of China under Grant No. LY19H090018, Zhejiang Province Medicine Health General Research Program (2020KY602) and the National Natural Science Foundation of China under Grant 81401038

\section{Disclosure}

The authors report no conflicts of interest in this work.

\section{References}

1. Thery C, Witwer KW, Aikawa E, et al. Minimal information for studies of extracellular vesicles 2018 (MISEV2018): a position statement of the International Society for Extracellular Vesicles and update of the MISEV2014 guidelines. J Extracell Vesicles. 2018;7(1):1535750.

2. Yang D, Zhang W, Zhang H, et al. Progress, opportunity, and perspective on exosome isolation - efforts for efficient exosome-based theranostics. Theranostics. 2020;10 (8):3684-3707. doi:10.7150/thno.41580

3. Sims B, Gu L, Krendelchtchikov A, Matthews QL. Neural stem cell-derived exosomes mediate viral entry. Int J Nanomedicine. 2014;9:4893-4897. doi:10.2147/IJN.S70999

4. Faure J, Lachenal G, Court M, et al. Exosomes are released by cultured cortical neurones. Mol Cell Neurosci. 2006;31 (4):642-648. doi:10.1016/j.mcn.2005.12.003

5. Sharma P, Schiapparelli L, Cline HT. Exosomes function in cell-cell communication during brain circuit development. Curr Opin Neurobiol. 2013;23(6):997-1004. doi:10.1016/j. conb.2013.08.005

6. Kalra H, Simpson RJ, Ji H, et al. Vesiclepedia: a compendium for extracellular vesicles with continuous community annotation. PLoS Biol. 2012;10(12):e1001450. doi:10.1371/journal. pbio. 1001450

7. Bergsmedh A, Szeles A, Henriksson M, et al. Horizontal transfer of oncogenes by uptake of apoptotic bodies. Proc Natl Acad Sci US A. 2001;98(11):6407-6411. doi:10.1073/pnas.101129998

8. Gregory CD, Dransfield I. Apoptotic tumor cell-derived extracellular vesicles as important regulators of the onco-regenerative niche. Front Immunol. 2018;9:1111. doi:10.3389/ fimmu.2018.01111

9. Kalluri R, LeBleu VS. The biology, function, and biomedical applications of exosomes. Science. 2020;367(6478):eaau6977. doi:10.1126/science.aau6977

10. Raposo G, Nijman HW, Stoorvogel W, et al. B lymphocytes secrete antigen-presenting vesicles. $J$ Exp Med. 1996;183 (3):1161-1172. doi:10.1084/jem.183.3.1161

11. Wolfers J, Lozier A, Raposo G, et al. Tumor-derived exosomes are a source of shared tumor rejection antigens for CTL cross-priming. Nat Med. 2001;7(3):297-303. doi:10.1038/85438

12. Hurley JH. ESCRTs are everywhere. EMBO J. 2015;34 (19):2398-2407. doi:10.15252/embj.201592484 
13. Zhen Y, Stenmark H. Cellular functions of Rab GTPases at a glance. $J$ Cell Sci. 2015;128(17):3171-3176. doi:10.1242/ jcs. 166074

14. Ostrowski M, Carmo NB, Krumeich S, et al. Rab27a and Rab27b control different steps of the exosome secretion pathway. Nat Cell Biol. 2010;12(1):19-30. doi:10.1038/ncb2000

15. Gross JC, Chaudhary V, Bartscherer K, Boutros M. Active Wnt proteins are secreted on exosomes. Nat Cell Biol. 2012;14 (10):1036-1045. doi:10.1038/ncb2574

16. Verweij FJ, Bebelman MP, Jimenez CR, et al. Quantifying exosome secretion from single cells reveals a modulatory role for GPCR signaling. $J$ Cell Biol. 2018;217(3):1129-1142. doi:10.1083/jcb.201703206

17. Sedgwick AE, D'Souza-Schorey C. The biology of extracellular microvesicles. Traffic. 2018;19(5):319-327. doi:10.1111/ tra. 12558

18. Granger E, McNee G, Allan V, Woodman P. The role of the cytoskeleton and molecular motors in endosomal dynamics. Semin Cell Dev Biol. 2014;31:20-29. doi:10.1016/j. semcdb.2014.04.011

19. Valadi H, Ekstrom K, Bossios A, Sjostrand M, Lee JJ, Lotvall JO. Exosome-mediated transfer of mRNAs and microRNAs is a novel mechanism of genetic exchange between cells. Nat Cell Biol. 2007;9(6):654-659. doi:10.1038/ncb1596

20. Ratajczak J, Miekus K, Kucia M, et al. Embryonic stem cell-derived microvesicles reprogram hematopoietic progenitors: evidence for horizontal transfer of mRNA and protein delivery. Leukemia. 2006;20(5):847-856. doi:10.1038/sj.leu.2404132

21. Skog J, Wurdinger T, van Rijn S, et al. Glioblastoma microvesicles transport RNA and proteins that promote tumour growth and provide diagnostic biomarkers. Nat Cell Biol. 2008;10 (12):1470-1476. doi:10.1038/ncb1800

22. Tkach M, Kowal J, Zucchetti AE, et al. Qualitative differences in T-cell activation by dendritic cell-derived extracellular vesicle subtypes. EMBO J. 2017;36(20):3012-3028. doi:10.15252/ embj.201696003

23. Cossetti C, Iraci N, Mercer TR, et al. Extracellular vesicles from neural stem cells transfer IFN-gamma via Ifngr1 to activate Stat1 signaling in target cells. Mol Cell. 2014;56(2):193-204. doi:10.1016/j.molcel.2014.08.020

24. Robbins PD, Morelli AE. Regulation of immune responses by extracellular vesicles. Nat Rev Immunol. 2014;14(3):195-208. doi: $10.1038 /$ nri3622

25. Stefanius K, Servage K, de Souza Santos M, et al. Human pancreatic cancer cell exosomes, but not human normal cell exosomes, act as an initiator in cell transformation. Elife. 2019;8:e40226. doi:10.7554/eLife.40226

26. Le MT, Hamar P, Guo C, et al. miR-200-containing extracellular vesicles promote breast cancer cell metastasis. $J$ Clin Invest. 2014;124(12):5109-5128. doi:10.1172/JCI75695

27. Zhou W, Fong MY, Min Y, et al. Cancer-secreted miR-105 destroys vascular endothelial barriers to promote metastasis. Cancer Cell. 2014;25(4):501-515. doi:10.1016/j.ccr.2014.03.007

28. Ricklefs FL, Alayo Q, Krenzlin H, et al. Immune evasion mediated by PD-L1 on glioblastoma-derived extracellular vesicles. Sci $A d v$. 2018;4(3):eaar2766. doi:10.1126/sciadv.aar2766

29. Konoshenko MY, Lekchnov EA, Vlassov AV, Laktionov PP. Isolation of extracellular vesicles: general methodologies and latest trends. Biomed Res Int. 2018;2018:8545347. doi:10.1155/ 2018/8545347

30. Onodi Z, Pelyhe C, Terezia Nagy C, et al. Isolation of high-purity extracellular vesicles by the combination of iodixanol density gradient ultracentrifugation and bind-elute chromatography from blood plasma. Front Physiol. 2018;9:1479. doi:10.3389/ fphys.2018.01479
31. He L, Zhu D, Wang J, Wu X. A highly efficient method for isolating urinary exosomes. Int J Mol Med. 2019;43(1):83-90. doi:10.3892/ijmm.2018.3944

32. Patel GK, Khan MA, Zubair H, et al. Comparative analysis of exosome isolation methods using culture supernatant for optimum yield, purity and downstream applications. Sci Rep. 2019;9 (1):5335. doi:10.1038/s41598-019-41800-2

33. Taylor DD, Shah S. Methods of isolating extracellular vesicles impact down-stream analyses of their cargoes. Methods. 2015;87:3-10. doi:10.1016/j.ymeth.2015.02.019

34. Gyorgy B, Modos K, Pallinger E, et al. Detection and isolation of cell-derived microparticles are compromised by protein complexes resulting from shared biophysical parameters. Blood. 2011;117(4):e39-e48. doi:10.1182/blood-2010-09307595

35. Dragovic RA, Gardiner C, Brooks AS, et al. Sizing and phenotyping of cellular vesicles using Nanoparticle Tracking Analysis. Nanomedicine. 2011;7(6):780-788. doi:10.1016/j.nano.2011.04.003

36. Momen-Heravi F, Balaj L, Alian S, et al. Alternative methods for characterization of extracellular vesicles. Front Physiol. 2012;3:354. doi:10.3389/fphys.2012.00354

37. Jarroux J, Morillon A, Pinskaya M. History, discovery, and classification of lncRNAs. Adv Exp Med Biol. 2017;1008:1-46.

38. Conigliaro A, Costa V, Lo Dico A, et al. CD90+ liver cancer cells modulate endothelial cell phenotype through the release of exosomes containing H19 lncRNA. Mol Cancer. 2015;14:155. doi:10.1186/s12943-015-0426-x

39. Liu Y, Zou R, Wang Z, Wen C, Zhang F, Lin F. Exosomal KLF3-AS1 from hMSCs promoted cartilage repair and chondrocyte proliferation in osteoarthritis. Biochem J. 2018;475 (22):3629-3638. doi:10.1042/BCJ20180675

40. Li Y, Zheng Q, Bao C, et al. Circular RNA is enriched and stable in exosomes: a promising biomarker for cancer diagnosis. Cell Res. 2015;25(8):981-984. doi:10.1038/cr.2015.82

41. Wang Y, Liu J, Ma J, et al. Exosomal circRNAs: biogenesis, effect and application in human diseases. Mol Cancer. 2019;18 (1):116. doi:10.1186/s12943-019-1041-z

42. Zhang $\mathrm{X}$, Wang $\mathrm{S}$, Wang $\mathrm{H}$, et al. Circular RNA circNRIP1 acts as a microRNA-149-5p sponge to promote gastric cancer progression via the AKT1/mTOR pathway. Mol Cancer. 2019;18(1):20. doi:10.1186/s12943-018-0935-5

43. Qian L, Yu S, Chen Z, Meng Z, Huang S, Wang P. The emerging role of circRNAs and their clinical significance in human cancers. Biochim Biophys Acta Rev Cancer. 2018;1870(2):247-260. doi:10.1016/j.bbcan.2018.06.002

44. Zhang H, Zhu L, Bai M, et al. Exosomal circRNA derived from gastric tumor promotes white adipose browning by targeting the miR-133/PRDM16 pathway. Int $J$ Cancer. 2019;144 (10):2501-2515. doi:10.1002/ijc.31977

45. Tian L, Cao J, Jiao H, et al. CircRASSF2 promotes laryngeal squamous cell carcinoma progression by regulating the miR-302b-3p/IGF-1R axis. Clin Sci (Lond). 2019;133 (9):1053-1066. doi:10.1042/CS20190110

46. Li Z, Yanfang W, Li J, et al. Tumor-released exosomal circular RNA PDE8A promotes invasive growth via the miR-338/MACC1/MET pathway in pancreatic cancer. Cancer Lett. 2018;432:237-250. doi:10.1016/j. canlet.2018.04.035

47. Li L, Li W, Chen N, et al. FLI1 exonic circular RNAs as a novel oncogenic driver to promote tumor metastasis in small cell lung cancer. Clin Cancer Res. 2019;25(4):1302-1317. doi:10.1158/ 1078-0432.CCR-18-1447

48. Batiz LF, Castro MA, Burgos PV, et al. Exosomes as novel regulators of adult neurogenic niches. Front Cell Neurosci. 2015;9:501. doi:10.3389/fncel.2015.00501 
49. Zhao C, Sun G, Li S, Shi Y. A feedback regulatory loop involving microRNA-9 and nuclear receptor TLX in neural stem cell fate determination. Nat Struct Mol Biol. 2009;16(4):365-371. doi:10.1038/nsmb.1576

50. Zhao C, Sun G, Li S, et al. MicroRNA let-7b regulates neural stem cell proliferation and differentiation by targeting nuclear receptor TLX signaling. Proc Natl Acad Sci U S A. 2010;107 (5):1876-1881. doi:10.1073/pnas.0908750107

51. Sharma P, Mesci P, Carromeu C, et al. Exosomes regulate neurogenesis and circuit assembly. Proc Natl Acad Sci U S A. 2019;116 (32):16086-16094. doi:10.1073/pnas.1902513116

52. Holm MM, Kaiser J, Schwab ME. Extracellular vesicles: multimodal envoys in neural maintenance and repair. Trends Neurosci. 2018;41(6):360-372. doi:10.1016/j.tins.2018.03.006

53. Mateos-Aparicio P, Rodriguez-Moreno A. Calcium dynamics and synaptic plasticity. Adv Exp Med Biol. 2020;1131(965-984).

54. Lachenal G, Pernet-Gallay K, Chivet M, et al. Release of exosomes from differentiated neurons and its regulation by synaptic glutamatergic activity. Mol Cell Neurosci. 2011;46(2):409-418. doi:10.1016/j.mcn.2010.11.004

55. Chivet M, Javalet C, Hemming F, et al. Exosomes as a novel way of interneuronal communication. Biochem Soc Trans. 2013;41 (1):241-244. doi:10.1042/BST20120266

56. Korkut C, Ataman B, Ramachandran P, et al. Trans-synaptic transmission of vesicular Wnt signals through Evi/Wntless. Cell. 2009;139(2):393-404. doi:10.1016/j.cell.2009.07.051

57. Koles K, Nunnari J, Korkut C, et al. Mechanism of evenness interrupted (Evi)-exosome release at synaptic boutons. $J$ Biol Chem. 2012;287(20):16820-16834. doi:10.1074/jbc. M112.342667

58. Ashley J, Cordy B, Lucia D, Fradkin LG, Budnik V, Thomson T. Retrovirus-like Gag protein Arc1 binds RNA and traffics across synaptic boutons. Cell. 2018;172(1-2):262-274 e211. doi:10.1016/j.cell.2017.12.022

59. Bahrini I, Song JH, Diez D, Hanayama R. Neuronal exosomes facilitate synaptic pruning by up-regulating complement factors in microglia. Sci Rep. 2015;5:7989. doi:10.1038/srep07989

60. Falker C, Hartmann A, Guett I, et al. Exosomal cellular prion protein drives fibrillization of amyloid beta and counteracts amyloid beta-mediated neurotoxicity. $J$ Neurochem. 2016;137 (1):88-100. doi:10.1111/jnc. 13514

61. Yuyama K, Sun H, Usuki S, et al. A potential function for neuronal exosomes: sequestering intracerebral amyloid-beta peptide. FEBS Lett. 2015;589(1):84-88. doi:10.1016/j. febslet.2014.11.027

62. Asai H, Ikezu S, Tsunoda S, et al. Depletion of microglia and inhibition of exosome synthesis halt tau propagation. Nat Neurosci. 2015;18(11):1584-1593. doi:10.1038/nn.4132

63. Stuendl A, Kunadt M, Kruse N, et al. Induction of alphasynuclein aggregate formation by CSF exosomes from patients with Parkinson's disease and dementia with Lewy bodies. Brain. 2016;139(2):481-494. doi:10.1093/brain/awv346

64. Basso M, Pozzi S, Tortarolo M, et al. Mutant copper-zinc superoxide dismutase (SOD1) induces protein secretion pathway alterations and exosome release in astrocytes: implications for disease spreading and motor neuron pathology in amyotrophic lateral sclerosis. J Biol Chem. 2013;288(22):15699-15711. doi:10.1074/jbc.M112.425066

65. Iguchi Y, Eid L, Parent M, et al. Exosome secretion is a key pathway for clearance of pathological TDP-43. Brain. 2016;139 (12):3187-3201. doi:10.1093/brain/aww237

66. Niu M, Li Y, Li G, et al. A longitudinal study on alpha-synuclein in plasma neuronal exosomes as a biomarker for Parkinson's disease development and progression. Eur J Neurol. 2020;27 (6):967-974. doi:10.1111/ene.14208
67. Zhao ZH, Chen ZT, Zhou RL, Zhang X, Ye QY, Wang YZ. Increased DJ-1 and alpha-synuclein in plasma neural-derived exosomes as potential markers for parkinson's disease. Front Aging Neurosci. 2018;10:438. doi:10.3389/fnagi.2018.00438

68. Jiang C, Hopfner F, Katsikoudi A, et al. Serum neuronal exosomes predict and differentiate Parkinson's disease from atypical parkinsonism. J Neurol Neurosurg Psychiatry. 2020;91 (7):720-729. doi:10.1136/jnnp-2019-322588

69. Cao Z, Wu Y, Liu G, et al. alpha-Synuclein in salivary extracellular vesicles as a potential biomarker of Parkinson's disease. Neurosci Lett. 2019;696:114-120. doi:10.1016/j. neulet.2018.12.030

70. Si X, Tian J, Chen Y, Yan Y, Pu J, Zhang B. Central nervous system-derived exosomal alpha-synuclein in serum may be a biomarker in parkinson's disease. Neuroscience. 2019;413:308-316. doi:10.1016/j.neuroscience.2019.05.015

71. Shi M, Liu C, Cook TJ, et al. Plasma exosomal alpha-synuclein is likely CNS-derived and increased in Parkinson's disease. Acta Neuropathol. 2014;128(5):639-650. doi:10.1007/s00401-0141314-y

72. Fraser KB, Rawlins AB, Clark RG, et al. Ser(P)-1292 LRRK2 in urinary exosomes is elevated in idiopathic Parkinson's disease. Mov Disord. 2016;31(10):1543-1550. doi:10.1002/mds.26686

73. Gui Y, Liu H, Zhang L, Lv W, Hu X. Altered microRNA profiles in cerebrospinal fluid exosome in Parkinson disease and Alzheimer disease. Oncotarget. 2015;6(35):37043-37053. doi:10.18632/oncotarget.6158

74. Wang Q, Han CL, Wang KL, et al. Integrated analysis of exosomal lncRNA and mRNA expression profiles reveals the involvement of lnc-MKRN2-42:1 in the pathogenesis of Parkinson's disease. CNS Neurosci Ther. 2020;26(5):527-537.

75. Mendes-Pinheiro B, Anjo SI, Manadas B, et al. Bone marrow mesenchymal stem cells' secretome exerts neuroprotective effects in a parkinson's disease rat model. Front Bioeng Biotechnol. 2019;7:294.

76. Chen HX, Liang FC, Gu P, et al. Exosomes derived from mesenchymal stem cells repair a Parkinson's disease model by inducing autophagy. Cell Death Dis. 2020;11(4):288. doi:10.1038/s41419-020-2473-5

77. Haney MJ, Klyachko NL, Zhao Y, et al. Exosomes as drug delivery vehicles for Parkinson's disease therapy. $J$ Control Release. 2015;207:18-30. doi:10.1016/j.jconrel.2015.03.033

78. Kojima R, Bojar D, Rizzi G, et al. Designer exosomes produced by implanted cells intracerebrally deliver therapeutic cargo for Parkinson's disease treatment. Nat Commun. 2018;9(1):1305. doi:10.1038/s41467-018-03733-8

79. Cooper JM, Wiklander PB, Nordin JZ, et al. Systemic exosomal siRNA delivery reduced alpha-synuclein aggregates in brains of transgenic mice. Mov Disord. 2014;29(12):1476-1485. doi: $10.1002 / \mathrm{mds} .25978$

80. Izco M, Blesa J, Schleef M, et al. Systemic exosomal delivery of shRNA minicircles prevents parkinsonian pathology. Mol Ther. 2019;27(12):2111-2122. doi:10.1016/j.ymthe.2019.08.010

81. Qu M, Lin Q, Huang L, et al. Dopamine-loaded blood exosomes targeted to brain for better treatment of Parkinson's disease. J Control Release. 2018;287:156-166. doi:10.1016/j. jconrel.2018.08.035

82. Sun R, Wang H, Shi Y, Sun Z, Jiang H, Zhang J. Changes in the morphology, number, and pathological protein levels of plasma exosomes may help diagnose alzheimer's disease. J Alzheimers Dis. 2020;73(3):909-917. doi:10.3233/JAD-190497

83. Nam E, Lee YB, Moon C, Chang KA. Serum tau proteins as potential biomarkers for the assessment of alzheimer's disease progression. Int J Mol Sci. 2020;21(14):5007. doi:10.3390/ ijms21145007 
84. Hamlett ED, Goetzl EJ, Ledreux A, et al. Neuronal exosomes reveal Alzheimer's disease biomarkers in Down syndrome. Alzheimers Dement. 2017;13(5):541-549. doi:10.1016/j. jalz.2016.08.012

85. Hamlett ED, LaRosa A, Mufson EJ, Fortea J, Ledreux A, Granholm AC. Exosome release and cargo in Down syndrome. Dev Neurobiol. 2019;79(7):639-655. doi:10.1002/dneu.22712

86. Jain G, Stuendl A, Rao P, et al. A combined miRNA-piRNA signature to detect Alzheimer's disease. Transl Psychiatry. 2019;9(1):250. doi:10.1038/s41398-019-0579-2

87. Yang L, Zhai Y, Hao Y, Zhu Z, Cheng G. The regulatory functionality of exosomes derived from hUMSCs in 3D culture for alzheimer's disease therapy. Small. 2020;16(3):e1906273. doi:10.1002/smll.201906273

88. Nakano M, Kubota K, Kobayashi E, et al. Bone marrow-derived mesenchymal stem cells improve cognitive impairment in an Alzheimer's disease model by increasing the expression of microRNA-146a in hippocampus. Sci Rep. 2020;10(1):10772. doi:10.1038/s41598-020-67460-1

89. Wang H, Sui H, Zheng Y, et al. Curcumin-primed exosomes potently ameliorate cognitive function in $\mathrm{AD}$ mice by inhibiting hyperphosphorylation of the Tau protein through the AKT/ GSK-3beta pathway. Nanoscale. 2019;11(15):7481-7496. doi:10.1039/C9NR01255A

90. Qi Y, Guo L, Jiang Y, Shi Y, Sui H, Zhao L. Brain delivery of quercetin-loaded exosomes improved cognitive function in $\mathrm{AD}$ mice by inhibiting phosphorylated tau-mediated neurofibrillary tangles. Drug Deliv. 2020;27(1):745-755. doi:10.1080/ 10717544.2020.1762262

91. Hayashi N, Doi H, Kurata Y, et al. Proteomic analysis of exosome-enriched fractions derived from cerebrospinal fluid of amyotrophic lateral sclerosis patients. Neurosci Res. 2019;S0168S0102(19):.30487

92. Thompson AG, Gray E, Mager I, et al. CSF extracellular vesicle proteomics demonstrates altered protein homeostasis in amyotrophic lateral sclerosis. Clin Proteomics. 2020;17:31. doi:10.1186/s12014-020-09294-7

93. Katsu M, Hama Y, Utsumi J, et al. MicroRNA expression profiles of neuron-derived extracellular vesicles in plasma from patients with amyotrophic lateral sclerosis. Neurosci Lett. 2019;708:134176. doi:10.1016/j.neulet.2019.03.048

94. Saucier D, Wajnberg G, Roy J, et al. Identification of a circulating miRNA signature in extracellular vesicles collected from amyotrophic lateral sclerosis patients. Brain Res. 2019;1708:100-108. doi:10.1016/j.brainres.2018.12.016

95. Lee M, Ban JJ, Kim KY, et al. Adipose-derived stem cell exosomes alleviate pathology of amyotrophic lateral sclerosis in vitro. Biochem Biophys Res Commun. 2016;479(3):434-439. doi:10.1016/j.bbrc.2016.09.069

96. Bonafede R, Brandi J, Manfredi M, et al. The anti-apoptotic effect of ASC-exosomes in an in vitro ALS model and their proteomic analysis. Cells. 2019;8(9):1087. doi:10.3390/cells8091087

97. Bonafede R, Turano E, Scambi I, et al. ASC-exosomes ameliorate the disease progression in SOD1(G93A) murine model underlining their potential therapeutic use in human ALS. Int $J \mathrm{Mol}$ Sci. 2020;21(10):3651. doi:10.3390/ijms21103651

98. Wang G, Dinkins M, He Q, et al. Astrocytes secrete exosomes enriched with proapoptotic ceramide and prostate apoptosis response 4 (PAR-4): potential mechanism of apoptosis induction in Alzheimer disease (AD). J Biol Chem. 2012;287 (25):21384-21395. doi:10.1074/jbc.M112.340513

99. Ubhi K, Peng K, Lessig S, et al. Neuropathology of dementia with Lewy bodies in advanced age: a comparison with Alzheimer disease. Neurosci Lett. 2010;485(3):222-227. doi:10.1016/j. neulet.2010.09.016
100. Colom-Cadena M, Grau-Rivera O, Planellas L, et al. Regional overlap of pathologies in lewy body disorders. J Neuropathol Exp Neurol. 2017;76(3):216-224. doi:10.1093/jnen/nlx002

101. Gamez-Valero A, Campdelacreu J, Rene R, Beyer K, Borras FE. Comprehensive proteomic profiling of plasma-derived Extracellular Vesicles from dementia with Lewy Bodies patients. Sci Rep. 2019;9(1):13282. doi:10.1038/s41598-019-49668-y

102. Gamez-Valero A, Campdelacreu J, Vilas D, et al. Exploratory study on microRNA profiles from plasma-derived extracellular vesicles in Alzheimer's disease and dementia with Lewy bodies. Transl Neurodegener. 2019;8:31. doi:10.1186/s40035-019-0169-5

103. Chen Y, Song Y, Huang J, et al. Increased circulating exosomal miRNA-223 is associated with acute ischemic stroke. Front Neurol. 2017;8:57. doi:10.3389/fneur.2017.00057

104. Ji Q, Ji Y, Peng J, et al. Increased brain-specific MiR-9 and MiR-124 in the serum exosomes of acute ischemic stroke patients. PLoS One. 2016;11(9):e0163645. doi:10.1371/journal. pone.0163645

105. Kerr N, Garcia-Contreras M, Abbassi S, et al. Inflammasome proteins in serum and serum-derived extracellular vesicles as biomarkers of stroke. Front Mol Neurosci. 2018;11:309. doi:10.3389/fnmol.2018.00309

106. Gui $\mathrm{Y}, \mathrm{Xu} \mathrm{Z}$, Jin $\mathrm{T}$, et al. Using extracellular circulating microRNAs to classify the etiological subtypes of ischemic stroke. Transl Stroke Res. 2019;10(4):352-361. doi:10.1007/ s12975-018-0659-2

107. Kalani MYS, Alsop E, Meechoovet B, et al. Extracellular microRNAs in blood differentiate between ischaemic and haemorrhagic stroke subtypes. J Extracell Vesicles. 2020;9 (1):1713540. doi:10.1080/20013078.2020.1713540

108. Chi NF, Chiou HY, Chou SY, et al. Hyperglycemia-related FAS gene and hsa-let-7b-5p as markers of poor outcomes for ischaemic stroke. Eur J Neurol. 2020;27(8):1647-1655. doi:10.1111/ene.14288

109. Doeppner TR, Herz J, Gorgens A, et al. Extracellular vesicles improve post-stroke neuroregeneration and prevent postischemic immunosuppression. Stem Cells Transl Med. 2015;4 (10):1131-1143. doi:10.5966/sctm.2015-0078

110. Otero-Ortega L, Laso-Garcia F, Gomez-de Frutos MD, et al. White matter repair after extracellular vesicles administration in an experimental animal model of subcortical stroke. Sci Rep. 2017;7:44433. doi:10.1038/srep44433

111. Moon GJ, Sung JH, Kim DH, et al. Application of Mesenchymal Stem Cell-Derived Extracellular Vesicles for Stroke: biodistribution and MicroRNA Study. Transl Stroke Res. 2019;10 (5):509-521. doi:10.1007/s12975-018-0668-1

112. Webb RL, Kaiser EE, Jurgielewicz BJ, et al. Human neural stem cell extracellular vesicles improve recovery in a porcine model of ischemic stroke. Stroke. 2018;49(5):1248-1256. doi:10.1161/ STROKEAHA.117.020353

113. Zheng X, Zhang L, Kuang Y, et al. Extracellular vesicles derived from neural progenitor cells-a preclinical evaluation for stroke treatment in mice. Transl Stroke Res. 2020;12:185-203. doi:10.1007/s12975-020-00814-z

114. Lapchak PA, Boitano PD, de Couto G, Marban E. Intravenous xenogeneic human cardiosphere-derived cell extracellular vesicles (exosomes) improves behavioral function in small-clot embolized rabbits. Exp Neurol. 2018;307:109-117. doi:10.1016/j. expneurol.2018.06.007

115. Yang J, Zhao Y, Zhang L, et al. RIPK3/MLKL-mediated neuronal necroptosis modulates the M1/M2 polarization of microglia/ macrophages in the ischemic cortex. Cereb Cortex. 2018;28 (7):2622-2635. doi:10.1093/cercor/bhy089

116. Ghosh M, Xu Y, Pearse DD. Cyclic AMP is a key regulator of M1 to M2a phenotypic conversion of microglia in the presence of Th2 cytokines. J Neuroinflammation. 2016;13:9. doi:10.1186/s12974015-0463-9 
117. Brifault C, Gras M, Liot D, May V, Vaudry D, Wurtz O. Delayed pituitary adenylate cyclase-activating polypeptide delivery after brain stroke improves functional recovery by inducing $\mathrm{m} 2$ microglia/macrophage polarization. Stroke. 2015;46(2):520-528. doi:10.1161/STROKEAHA.114.006864

118. Zheng Y, He R, Wang P, Shi Y, Zhao L, Liang J. Exosomes from LPS-stimulated macrophages induce neuroprotection and functional improvement after ischemic stroke by modulating microglial polarization. Biomater Sci. 2019;7(5):2037-2049. doi:10.1039/C8BM01449C

119. Song Y, Li Z, He T, et al. M2 microglia-derived exosomes protect the mouse brain from ischemia-reperfusion injury via exosomal miR-124. Theranostics. 2019;9(10):2910-2923. doi:10.7150/ thno.30879

120. Tian T, Zhang HX, He CP, et al. Surface functionalized exosomes as targeted drug delivery vehicles for cerebral ischemia therapy. Biomaterials. 2018;150:137-149. doi:10.1016/j. biomaterials.2017.10.012

121. Yang J, Wu S, Hou L, et al. Therapeutic effects of simultaneous delivery of nerve growth factor mRNA and protein via exosomes on cerebral ischemia. Mol Ther Nucleic Acids. 2020;21:512-522. doi:10.1016/j.omtn.2020.06.013

122. Li F, Zhao L, Shi Y, Liang J. Edaravone-loaded macrophage-derived exosomes enhance neuroprotection in the rat permanent middle cerebral artery occlusion model of stroke. Mol Pharm. 2020;17(9):3192-3201. doi:10.1021/acs. molpharmaceut.0c00245

123. Xin H, Katakowski M, Wang F, et al. MicroRNA cluster miR-1792 cluster in exosomes enhance neuroplasticity and functional recovery after stroke in rats. Stroke. 2017;48(3):747-753. doi:10.1161/STROKEAHA.116.015204

124. Zhang $\mathrm{H}, \mathrm{Wu} \mathrm{J}, \mathrm{Wu}$ J, et al. Exosome-mediated targeted delivery of miR-210 for angiogenic therapy after cerebral ischemia in mice. J Nanobiotechnology. 2019;17(1):29. doi:10.1186/s12951019-0461-7

125. Venkat $\mathrm{P}$, Cui C, Chopp M, et al. MiR-126 mediates brain endothelial cell exosome treatment-induced neurorestorative effects after stroke in type 2 diabetes mellitus mice. Stroke. 2019;50(10):2865-2874. doi:10.1161/STROKEAHA.119.025371

126. Yang L, Han B, Zhang Z, et al. Extracellular vesicle-mediated delivery of circular RNA SCMH1 promotes functional recovery in rodent and nonhuman primate ischemic stroke models. Circulation. 2020;142(6):556-574. doi:10.1161/ CIRCULATIONAHA.120.045765

127. Mutch CA, Talbott JF, Gean A. Imaging evaluation of acute traumatic brain injury. Neurosurg Clin N Am. 2016;27 (4):409-439. doi:10.1016/j.nec.2016.05.011

128. Manek R, Moghieb A, Yang Z, et al. Protein biomarkers and neuroproteomics characterization of microvesicles/exosomes from human cerebrospinal fluid following traumatic brain injury. Mol Neurobiol. 2018;55(7):6112-6128. doi:10.1007/s12035-0170821-y

129. Cheng Y, Pereira M, Raukar N, et al. Potential biomarkers to detect traumatic brain injury by the profiling of salivary extracellular vesicles. J Cell Physiol. 2019;234(8):14377-14388. doi: $10.1002 /$ jcp. 28139

130. Wang $\mathrm{P}$, Ma $\mathrm{H}$, Zhang $\mathrm{Y}$, et al. Plasma exosome-derived microRNAs as novel biomarkers of traumatic brain injury in rats. Int J Med Sci. 2020;17(4):437-448. doi:10.7150/ijms.39667

131. Williams AM, Bhatti UF, Brown JF, et al. Early single-dose treatment with exosomes provides neuroprotection and improves blood-brain barrier integrity in swine model of traumatic brain injury and hemorrhagic shock. J Trauma Acute Care Surg. 2020;88(2):207-218. doi:10.1097/TA.0000000000002563
132. Williams AM, Wu Z, Bhatti UF, et al. Early single-dose exosome treatment improves neurologic outcomes in a 7-day swine model of traumatic brain injury and hemorrhagic shock. J Trauma Acute Care Surg. 2020;89(2):388-396. doi:10.1097/ TA.0000000000002698

133. Kim DK, Nishida H, An SY, Shetty AK, Bartosh TJ, Prockop DJ. Chromatographically isolated CD63+CD81+ extracellular vesicles from mesenchymal stromal cells rescue cognitive impairments after TBI. Proc Natl Acad Sci U S A. 2016;113 (1):170-175. doi:10.1073/pnas.1522297113

134. Ge X, Guo $\mathrm{M}, \mathrm{Hu} \mathrm{T}$, et al. Increased microglial exosomal miR-124-3p alleviates neurodegeneration and improves cognitive outcome after rmTBI. Mol Ther. 2020;28(2):503-522. doi:10.1016/j.ymthe.2019.11.017

135. Li Y, Yang YY, Ren JL, Xu F, Chen FM, Li A. Exosomes secreted by stem cells from human exfoliated deciduous teeth contribute to functional recovery after traumatic brain injury by shifting microglia M1/M2 polarization in rats. Stem Cell Res Ther. 2017;8 (1):198. doi:10.1186/s13287-017-0648-5

136. Ding SQ, Chen YQ, Chen J, et al. Serum exosomal microRNA transcriptome profiling in subacute spinal cord injured rats. Genomics. 2020;112(2):2092-2105. doi:10.1016/j. ygeno.2019.12.003

137. Romanelli P, Bieler L, Scharler C, et al. Extracellular vesicles can deliver anti-inflammatory and anti-scarring activities of mesenchymal stromal cells after spinal cord injury. Front Neurol. 2019;10:1225. doi:10.3389/fneur.2019.01225

138. Goncalves MB, Malmqvist T, Clarke E, et al. Neuronal RARbeta signaling modulates PTEN activity directly in neurons and via exosome transfer in astrocytes to prevent glial scar formation and induce spinal cord regeneration. $J$ Neurosci. 2015;35 (47):15731-15745. doi:10.1523/JNEUROSCI.1339-15.2015

139. Guo S, Perets N, Betzer O, et al. Intranasal delivery of mesenchymal stem cell derived exosomes loaded with phosphatase and tensin homolog siRNA repairs complete spinal cord injury. ACS Nano. 2019;13(9):10015-10028. doi:10.1021/acsnano.9b01892

140. Wang Z, Song Y, Han X, Qu P, Wang W. Long noncoding RNA PTENP1 affects the recovery of spinal cord injury by regulating the expression of miR-19b and miR-21. J Cell Physiol. 2020;235 (4):3634-3645. doi:10.1002/jcp.29253

141. Kang J, Li Z, Zhi Z, Wang S, Xu G. MiR-21 derived from the exosomes of MSCs regulates the death and differentiation of neurons in patients with spinal cord injury. Gene Ther. 2019;26 (12):491-503. doi:10.1038/s41434-019-0101-8

142. Xu G, Ao R, Zhi Z, Jia J, Yu B. miR-21 and miR-19b delivered by hMSC-derived EVs regulate the apoptosis and differentiation of neurons in patients with spinal cord injury. J Cell Physiol. 2019;234(7):10205-10217. doi:10.1002/jcp.27690

143. He J, Ren M, Li H, Yang L, Wang X, Yang Q. Exosomal circular RNA as a biomarker platform for the early diagnosis of immune-mediated demyelinating disease. Front Genet. 2019;10:860. doi:10.3389/fgene.2019.00860

144. Kutzelnigg A, Lassmann H. Pathology of multiple sclerosis and related inflammatory demyelinating diseases. Handb Clin Neurol. 2014;122:15-58

145. Ebrahimkhani S, Vafaee F, Young PE, et al. Exosomal microRNA signatures in multiple sclerosis reflect disease status. Sci Rep. 2017;7(1):14293. doi:10.1038/s41598-017-14301-3

146. Selmaj I, Cichalewska M, Namiecinska M, et al. Global exosome transcriptome profiling reveals biomarkers for multiple sclerosis. Ann Neurol. 2017;81(5):703-717. doi:10.1002/ana.24931

147. Manna I, Iaccino E, Dattilo V, et al. Exosome-associated miRNA profile as a prognostic tool for therapy response monitoring in multiple sclerosis patients. FASEB J. 2018;32(8):4241-4246. doi:10.1096/fj.201701533R 
148. Ebrahimkhani S, Beadnall HN, Wang C, et al. Serum exosome microRNAs predict multiple sclerosis disease activity after fingolimod treatment. Mol Neurobiol. 2020;57(2):1245-1258. doi:10.1007/s12035-019-01792-6

149. Chen C, Wu Y, Li M, et al. Different exosomal microRNA profile in aquaporin-4 antibody positive neuromyelitis optica spectrum disorders. Front Immunol. 2020;11:1064. doi:10.3389/ fimmu.2020.01064

150. Casella G, Colombo F, Finardi A, et al. Extracellular vesicles containing IL-4 modulate neuroinflammation in a mouse model of multiple sclerosis. Mol Ther. 2018;26(9):2107-2118. doi:10.1016/ j.ymthe.2018.06.024

151. Clark K, Zhang S, Barthe S, et al. Placental mesenchymal stem cell-derived extracellular vesicles promote myelin regeneration in an animal model of multiple sclerosis. Cells. 2019;8(12):1497. doi:10.3390/cells8121497

152. Hosseini Shamili F, Alibolandi $M$, Rafatpanah $H$, et al. Immunomodulatory properties of MSC-derived exosomes armed with high affinity aptamer toward mylein as a platform for reducing multiple sclerosis clinical score. J Control Release. 2019;299:149-164. doi:10.1016/j.jconrel.2019.02.032

153. Hyun KA, Kim J, Gwak H, Jung HI. Isolation and enrichment of circulating biomarkers for cancer screening, detection, and diagnostics. Analyst. 2016;141(2):382-392. doi:10.1039/ C5AN01762A

154. Figueroa JM, Skog J, Akers J, et al. Detection of wild-type EGFR amplification and EGFRvIII mutation in CSF-derived extracellular vesicles of glioblastoma patients. Neuro Oncol. 2017;19 (11):1494-1502. doi:10.1093/neuonc/nox085

155. Akers JC, Ramakrishnan V, Kim R, et al. miRNA contents of cerebrospinal fluid extracellular vesicles in glioblastoma patients. $J$ Neurooncol. 2015;123(2):205-216. doi:10.1007/s11060-0151784-3

156. Lan F, Qing Q, Pan Q, Hu M, Yu H, Yue X. Serum exosomal miR-301a as a potential diagnostic and prognostic biomarker for human glioma. Cell Oncol (Dordr). 2018;41(1):25-33. doi:10.1007/s13402-017-0355-3

157. Ricklefs FL, Maire CL, Matschke J, et al. FASN is a biomarker enriched in malignant glioma-derived extracellular vesicles. Int J Mol Sci. 2020;21(6):1931. doi:10.3390/ijms21061931

158. Garcia-Romero N, Carrion-Navarro J, Esteban-Rubio S, et al. DNA sequences within glioma-derived extracellular vesicles can cross the intact blood-brain barrier and be detected in peripheral blood of patients. Oncotarget. 2017;8(1):1416-1428. doi:10.18632/oncotarget. 13635
159. Indira Chandran V, Welinder C, Mansson AS, et al. Ultrasensitive immunoprofiling of plasma extracellular vesicles identifies syndecan-1 as a potential tool for minimally invasive diagnosis of glioma. Clin Cancer Res. 2019;25(10):3115-3127.

160. Melki I, Tessandier N, Zufferey A, Boilard E. Platelet microvesicles in health and disease. Platelets. 2017;28(3):214-221. doi:10.1080/09537104.2016.1265924

161. Al-Mufti F, Claassen J. Neurocritical care: status epilepticus review. Crit Care Clin. 2014;30(4):751-764. doi:10.1016/j.ccc.2014.06.006

162. Raoof R, Jimenez-Mateos EM, Bauer S, et al. Cerebrospinal fluid microRNAs are potential biomarkers of temporal lobe epilepsy and status epilepticus. Sci Rep. 2017;7(1):3328. doi:10.1038/ s41598-017-02969-6

163. Yan $\mathrm{S}$, Zhang $\mathrm{H}$, Xie $\mathrm{W}$, et al. Altered microRNA profiles in plasma exosomes from mesial temporal lobe epilepsy with hippocampal sclerosis. Oncotarget. 2017;8(3):4136-4146. doi:10.18632/oncotarget.13744

164. Lin Z, Gu Y, Zhou R, et al. Serum exosomal proteins F9 and TSP-1 as potential diagnostic biomarkers for newly diagnosed epilepsy. Front Neurosci. 2020;14:737. doi:10.3389/fnins.2020.00737

165. Upadhya D, Shetty AK. Promise of extracellular vesicles for diagnosis and treatment of epilepsy. Epilepsy Behav. 2019;106499. doi:10.1016/j.yebeh.2019.106499

166. Costa-Ferro ZS, Souza BS, Leal MM, et al. Transplantation of bone marrow mononuclear cells decreases seizure incidence, mitigates neuronal loss and modulates pro-inflammatory cytokine production in epileptic rats. Neurobiol Dis. 2012;46(2):302-313. doi:10.1016/j.nbd.2011.12.001

167. Long Q, Upadhya D, Hattiangady B, et al. Intranasal MSC-derived A1-exosomes ease inflammation, and prevent abnormal neurogenesis and memory dysfunction after status epilepticus. Proc Natl Acad Sci U S A. 2017;114(17):E3536E3545. doi:10.1073/pnas.1703920114

168. Cao XY, Lu JM, Zhao ZQ, et al. MicroRNA biomarkers of Parkinson's disease in serum exosome-like microvesicles. Neurosci Lett. 2017;644:94-99. doi:10.1016/j.neulet.2017.02.045

169. Yao YF, Qu MW, Li GC, Zhang FB, Rui HC. Circulating exosomal miRNAs as diagnostic biomarkers in Parkinson's disease. Eur Rev Med Pharmacol Sci. 2018;22(16):5278-5283. doi:10.26355/eurrev_201808_15727

170. Barbagallo C, Mostile G, Baglieri G, et al. Specific signatures of serum miRNAs as potential biomarkers to discriminate clinically similar neurodegenerative and vascular-related diseases. Cell $\mathrm{Mol}$ Neurobiol. 2020;40(4):531-546. doi:10.1007/s10571-019-00751-y

\section{Publish your work in this journal}

Clinical Interventions in Aging is an international, peer-reviewed journal focusing on evidence-based reports on the value or lack thereof of treatments intended to prevent or delay the onset of maladaptive correlates of aging in human beings. This journal is indexed on PubMed Central, MedLine, CAS, Scopus and the Elsevier
Bibliographic databases. The manuscript management system is completely online and includes a very quick and fair peer-review system, which is all easy to use. Visit http://www.dovepress.com/ testimonials.php to read real quotes from published authors. 